\title{
Wire laser metal deposition of $22 \%$ Cr duplex stainless steel: as-deposited and heat-treated microstructure and mechanical properties
}

\author{
Amir Baghdadchi ${ }^{1, *}$ (D), Vahid A. Hosseini ${ }^{1}$, Maria Asuncion Valiente Bermejo ${ }^{1}$, \\ Björn Axelsson ${ }^{2}$, Ebrahim Harati ${ }^{1,3}$, Mats Högström ${ }^{1}$, and Leif Karlsson ${ }^{1}$ \\ ${ }^{1}$ Department of Engineering Science, University West, 46186 Trollhättan, Sweden \\ ${ }^{2}$ Alfa Laval Tumba AB, 14780 Tumba, Sweden \\ ${ }^{3}$ ITW Welding $A B, 43325$ Partille, Sweden
}

Received: 11 August 2021

Accepted: 6 January 2022

Published online:

19 January 2022

(C) The Author(s) 2022

\begin{abstract}
Duplex stainless steel (DSS) blocks with dimensions of $150 \times 70 \times 30 \mathrm{~mm}^{3}$ were fabricated by Laser Metal Deposition with Wire (LMDw). Implementation of a programmable logic control system and the hot-wire technology provided a stable and consistent process producing high-quality and virtually defect-free deposits. Microstructure and mechanical properties were studied for as-deposited (AD) material and when heat-treated (HT) for $1 \mathrm{~h}$ at $1100{ }^{\circ} \mathrm{C}$. The AD microstructure was inhomogeneous with highly ferritic areas with nitrides and austenitic regions with fine secondary austenite occurring in a periodic manner. Heat treatment produced a homogenized microstructure, free from nitrides and fine secondary austenite, with balanced ferrite and austenite fractions. Although some nitrogen was lost during LMDw, heat treatment or reheating by subsequent passes in AD allowed the formation of about $50 \%$ austenite. Mechanical properties fulfilled common requirements on strength and toughness in both asdeposited and heat-treated conditions achieving the highest strength in $\mathrm{AD}$ condition and best toughness and ductility in HT condition. Epitaxial ferrite growth, giving elongated grains along the build direction, resulted in somewhat higher toughness in both AD and HT conditions when cracks propagated perpendicular to the build direction. It was concluded that high-quality components can be produced by LMDw and that deposits can be used in either AD or HT conditions. The findings of this research provide valuable input for the fabrication of high-performance DSS AM components.
\end{abstract}

Handling Editor: M. Grant Norton.

Address correspondence to E-mail: amir.baghdadchi@hv.se 


\section{GRAPHICAL ABSTRACT}
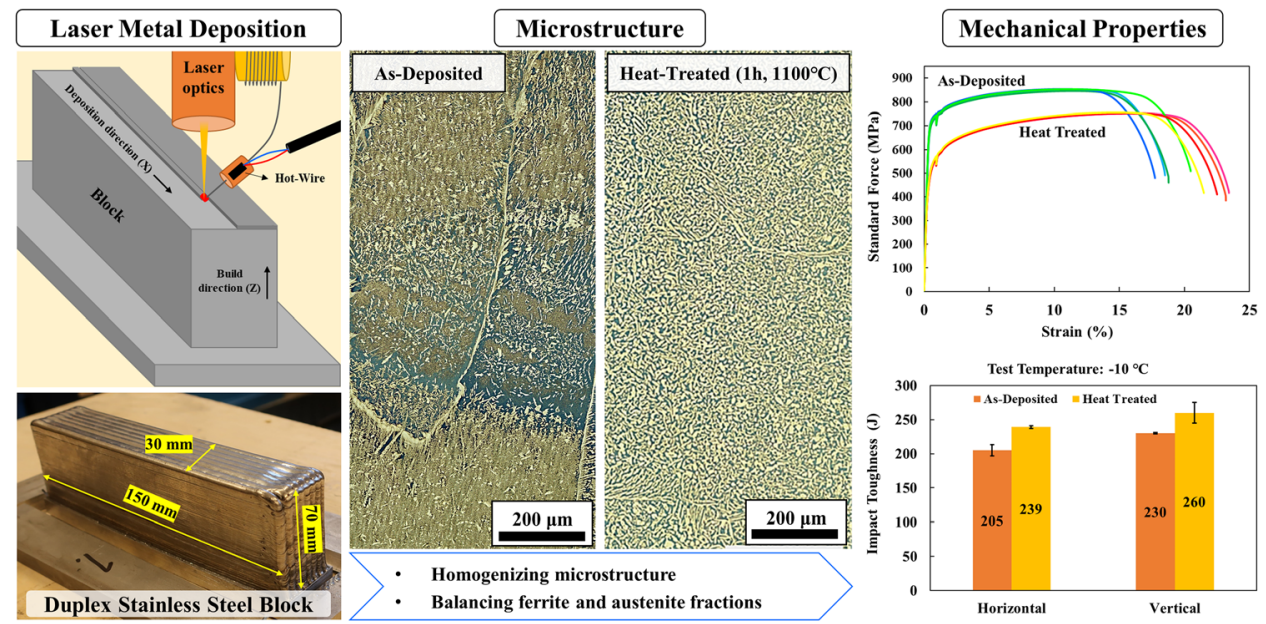

\section{Introduction}

Additive manufacturing (AM) provides new opportunities to fabricate near-net-shape components with a low waste of material, customized features, tailored properties, and complex geometries [1]. Unlike the subtractive methods which remove materials to reach the final shape, in AM processes, the parts are fabricated by adding beads/layers upon each other [2]. According to the American Society for Testing and Materials (ASTM International), AM of metallic materials is classified based on energy source, state of fusion, material feedstock, and process category [3]. In this classification, powder bed fusion (PBF) and direct energy deposition (DED) are the two main AM technologies for metallic materials. In PBF, metallic powder is used as the material feedstock, while in DED, both wire and powder can be deposited to build AM parts. In these processes, the source of energy could be a either laser beam, an electron beam, or an electric arc.

Laser Metal Deposition with Wire (LMDw) is a DED technology in which a laser beam is employed as the energy source to melt and deposit the wire to build the component. Important benefits of wire-feed AM are availability and low cost of raw material, high material usage efficiency (up to $100 \%$ ), and a possible high deposition rate. In addition, implementation of a laser beam in combination with an advanced controlling system provides easy monitoring and good control of the process [4]. This AM process is, therefore, suitable for the production of relatively large and fully dense metallic parts. Preheating the wire feedstock using the hot-wire technique increases the deposition rate of LMDw [5], thereby improving productivity. In the production of a large component, another alternative is wire-arc additive manufacturing (WAAM) which can achieve higher deposition rates compared to LMDw [6]. However, WAAM has less good-dimensional control and design limitations and the deposited product needs significant final machining [7]. Implementation of a laser beam instead of an electric arc as the power source has the advantage that dimensional control can be improved, while it also preserves a high deposition rate $[2,8]$.

Duplex stainless steels (DSSs), with a ferritic-austenitic microstructure, are used in a wide range of applications thanks to their combination of high corrosion resistance and excellent mechanical properties. The ferrite phase contributes to strength and resistance to stress corrosion cracking, while the austenite phase improves toughness and general corrosion resistance [9]. The optimum properties of these alloys come by approximately equal fractions of ferrite and austenite [10]. According to the formation mechanism, austenite can be divided into primary 
austenite and secondary austenite. Duplex stainless steels solidify fully ferritic and primary austenite form on cooling in a solid-state transformation of ferrite to austenite at ferrite/ferrite grain boundaries as well as inside the ferrite grains [11, 12], while secondary austenite form during additional subsequent reheating cycles. Reaching a proper phase balance is challenging when DSS is fabricated with low energy input processes such as laser welding or laser AM, in which the high cooling rate often results in an excessive amount of ferrite and nitride formation $[13,14]$. In the case of nitrogen loss, this will also restrict austenite formation, thereby affecting phase balance in DSS [15, 16]. Reheating of previously deposited layers when depositing following layers may cause the formation of secondary austenite and precipitation of detrimental secondary phases such as sigma and chi phase. Therefore, selection of process parameters plays a vital role in AM of DSS in determining the microstructure.

Additive manufacturing of DSS has recently been investigated in several studies. In powder bed fusion AM with selective laser melting (SLM) [9, 17-19], an excessive amount of ferrite formation is a problem and post-heat treatment has been necessary to balance the ferrite and austenite ratio. Wire-arc additive manufacturing of DSS has also attracted widespread interest due to the affordable equipment and its high deposition rate [20-24].

As summarized above, there is some research about powder bed AM and WAAM; however, knowledge is lacking about LMDw of DSS. Recently, Valiente et al. [4] studied the production of a singlebead wall DSS by LMDw as an initial stage of the current work. They produced a single-bead wall and studied the microstructure in both as-deposited and heat-treated conditions. The study is here extended to the production of relatively big blocks, aiming at enabling fabrication of high-quality, high-performance DSS components. As-deposited and heattreated microstructures were characterized by light optical microscopy and electron backscattered diffraction, and mechanical properties were evaluated by tensile and impact toughness tests. Thermodynamic calculations were also employed to study and understand the evolution of the microstructure. Finally, a comparison of as-deposited and heat-treated conditions revealed how the thermal cycles during $\mathrm{AM}$ and heat treatment, locally and globally, affect the microstructure and mechanical properties.

\section{Experimental}

\section{Materials}

In this study, $10 \mathrm{~mm}$-thick duplex stainless steel type 2205 (UNS S32205) was used as substrate material for the deposition. The feedstock was a solid wire duplex stainless steel of type 2209 (EN ISO 14343-A: G 229 $3 \mathrm{~N} \mathrm{~L}$ ) in $1.2 \mathrm{~mm}$ diameter. Table 1 presents the chemical composition of the substrate and the wire as given by the material producer certificates. The shielding gas used during LMDw was pure (99.99\%) argon.

\section{Additive manufacturing of blocks by Laser Metal Deposition with Wire}

A photograph of the LMDw setup consisting of a $6 \mathrm{~kW}$ Ytterbium-doped fiber laser, a 6-axis robot, a DED tool with an off-axis wire nozzle, laser optics, wire feeding system, control system, and actuators is shown in Fig. 1a. A programmable logic control (PLC) was employed to control the process. The LMDw setup was mounted on the industrial robot and the robot governed the movement of the deposition tool according to a set pattern. The process parameters used for the production of the LMDw blocks are listed in Table 2. To increase the deposition rate, a wire-feed system equipped with wire resistive pre-heating, commonly termed hot-wire technology, was implemented. The current and the voltage for pre-heating of the wire were regulated with an electrical power source and measured online and used for process monitoring and controlling. The aim of controlling was to keep a specific wire resistance to have a stable metal transfer, good wettability, and appropriate dimensional control. A schematic illustration of the LMDw approach $[4,5]$ is presented in Fig. 1b.

As indicated in Fig. 1b, deposition of each pass began from the starting line and was all made in the same direction. When finishing a pass, the laser returned to the starting line and subsequently deposited the next pass. There was no waiting time for cooling between passes or layers, and the LMDw was done continuously. The blocks that were $150 \mathrm{~mm}$ long, $70 \mathrm{~mm}$ in height, and $30 \mathrm{~mm}$ wide were produced by LMDw deposition of 60 layers, each layer consisting of 8 beads, in all 480 beads (Fig. 1c). The 
Table 1 Chemical composition of the plate and wire (wt.\%)

\begin{tabular}{llllllllllll}
\hline & $\mathrm{C}$ & $\mathrm{Si}$ & $\mathrm{Mn}$ & $\mathrm{P}$ & $\mathrm{S}$ & $\mathrm{Cr}$ & $\mathrm{Ni}$ & $\mathrm{Mo}$ & $\mathrm{Cu}$ & $\mathrm{N}$ & $\mathrm{Co}$ \\
\hline Plate & 0.016 & 0.32 & 1.77 & 0.027 & $<0.001$ & 22.77 & 5.50 & 3.07 & 0.21 & 0.177 & 0.096 \\
Wire & 0.016 & 0.45 & 1.45 & 0.016 & 0.001 & 23.23 & 8.62 & 3.29 & 0.04 & 0.160 & - \\
\hline
\end{tabular}
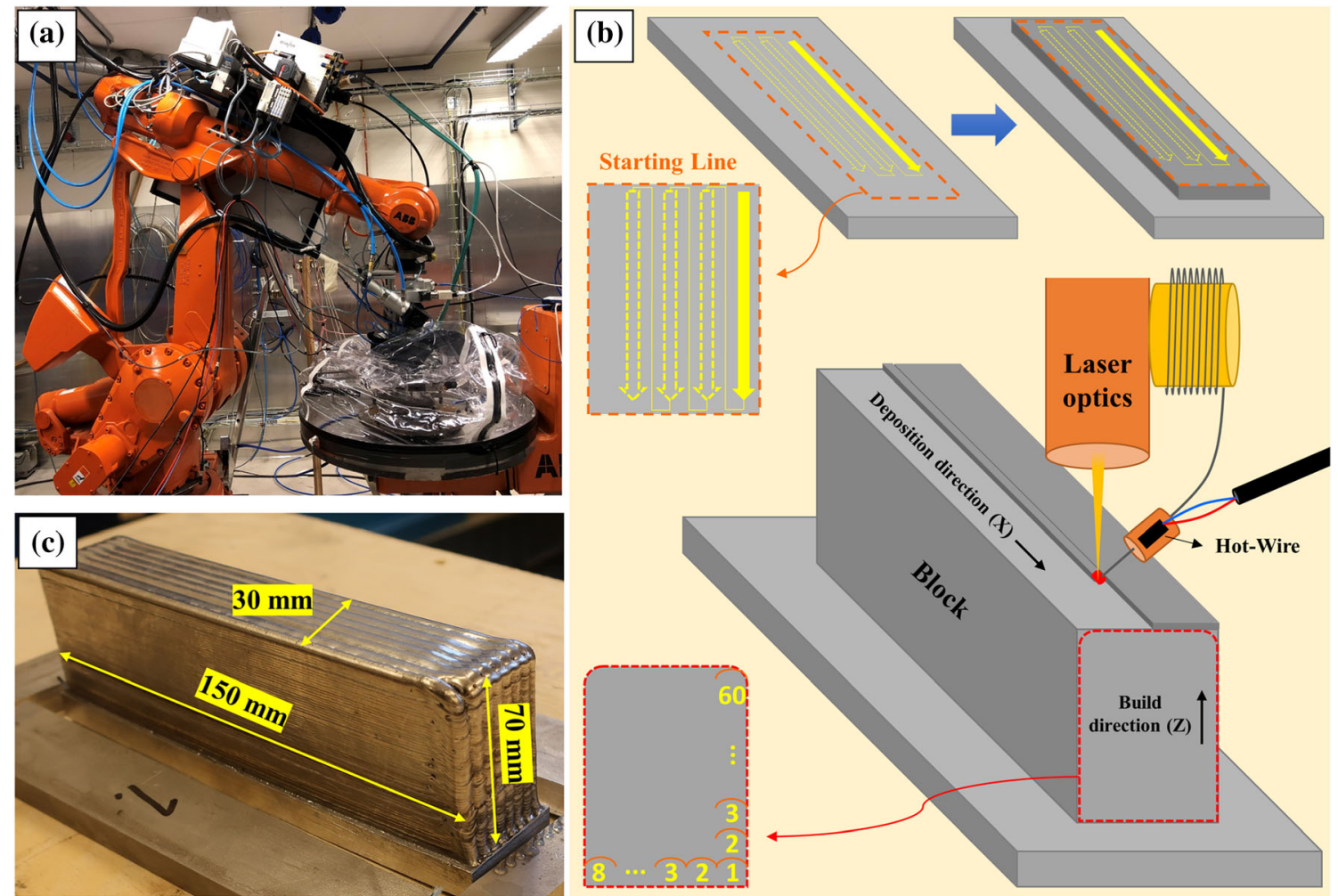

Figure 1 a Laser Metal Deposition setup [4], b schematic illustration of LMDw process, and $\mathbf{c}$ additively manufactured block.

Table 2 LMDw process parameters

\begin{tabular}{ll}
\hline Laser power $(\mathrm{W})$ & 3500 \\
Wire-feed rate $(\mathrm{m} / \mathrm{min})$ & 2 \\
Deposition speed $(\mathrm{mm} / \mathrm{s})$ & 10 \\
Focal length $(\mathrm{mm})$ & 300 \\
Wavelength $(\mathrm{nm})$ & 1040 \\
Hot-wire voltage $(\mathrm{V})$-Average value & $1.5 \mathrm{~V}$ in the first layer and $1 \mathrm{~V}$ in the subsequent layers \\
Hot-wire current $(\mathrm{A})$-Average values & $\sim 100 \mathrm{~A}$ in the first layer and $\sim 70 \mathrm{~A}$ in the subsequent layers \\
\hline
\end{tabular}

effective production time for deposition of each block was approximately $2 \mathrm{~h}$.

One block was investigated in as-deposited condition and one other after heat treatment. The heat treatment was performed in a furnace with an air atmosphere, and the temperature was controlled by the furnace thermocouple. The block was held for $1 \mathrm{~h}$ after reaching $1100{ }^{\circ} \mathrm{C}$ and cooled by water quenching. The heat treatment procedure was selected to achieve a balanced content of ferrite and austenite
[25], dissolution of nitrides, and avoiding sigma formation.

\section{Test samples}

Samples for microscopy and mechanical testing were extracted from different regions and directions to study homogeneity and isotropy of the as-deposited (AD) and heat-treated (HT) LMDw blocks. A schematic illustration of samples extracted for 
metallography inspection, chemical composition analysis, and mechanical tests is shown in Fig. 2.

\section{Microstructure characterization}

Microstructures of the blocks in as-deposited and heat-treated conditions were studied with light optical microscopy and scanning electron microscopy (SEM) including electron backscatter diffraction (EBSD) analysis.

For light optical microscopy, cross sections of the blocks were mounted, ground, and polished down to $0.05-\mu \mathrm{m}$ using alumina suspension in the last step. The polished samples were etched with two different reagents: (i) color etching with modified Beraha reagent $(60 \mathrm{ml}$ water, $30 \mathrm{ml} \mathrm{HCl}, 0.7 \mathrm{~g}$ potassium bisulfite) for $12 \mathrm{~s}$ for identification of ferrite and austenite and (ii) electrolytic etching using oxalic acid with a voltage of $4 \mathrm{~V}$ for $10 \mathrm{~s}$ for observation of nitrides [26, 27]. The latter etching method was also employed to reveal areas susceptible to local corrosion attacks [28]. A Zeiss Axio Imager.M2m optical microscope was used to study the microstructure in $\mathrm{AD}$ and HT conditions. Phase fraction measurements were performed by image analysis (IA) via the openaccess ImageJ software.

Ferrite numbers, moreover, were measured using a calibrated Fischer FERITOSCOPE $®$, MP30, on cross sections of both $\mathrm{AD}$ and HT blocks, and the average of 10 measurements was reported.

For EBSD analysis, cross sections after grinding were electropolished with an electrolyte solution consisting of $150 \mathrm{~g}$ citric acid, $300 \mathrm{~g}$ distilled water,

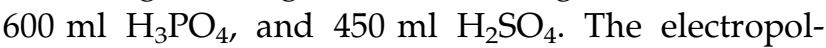
ishing was performed for $20 \mathrm{~s}$ at a voltage and a current density of $10 \mathrm{~V}$ and $1.5 \mathrm{~A} / \mathrm{cm}^{2}$, respectively. To avoid pitting corrosion, the electrolyte was cooled by an ice bath to allow polishing at around $0{ }^{\circ} \mathrm{C}$. It was found beneficial to lightly shake the sample while polishing to ensure continuous refreshment of the solution at the sample surface.

EBSD analysis was performed with a ZEISS Gemini SEM 450 equipped with a Symmetry S2 EBSD detector from Oxford Instruments. The acceleration voltage, sample tilt angle, and working distance were $20 \mathrm{kV}, 70^{\circ}$, and $12 \mathrm{~mm}$, respectively. Step sizes were $0.5 \mu \mathrm{m}$ and $0.7 \mu \mathrm{m}$ for $\mathrm{AD}$ and HT specimens, respectively. The AZtecCrystal 1.1 software from Oxford Instruments was used to analyze the EBSD results.

\section{Chemical analysis}

The chemical compositions at the bottom, middle, and top of blocks in both AD and HT conditions were analyzed by optical emission spectroscopy (OES). For each location, two points were selected and the OES analysis was done three times in each point. The results are presented as the average of the six analyses in each location. Nitrogen and oxygen contents, in addition, were measured by combustion analysis using a LECO TC-436 analyzer. The LECO tests were done in four different regions from bottom to top of the block cross-sections.

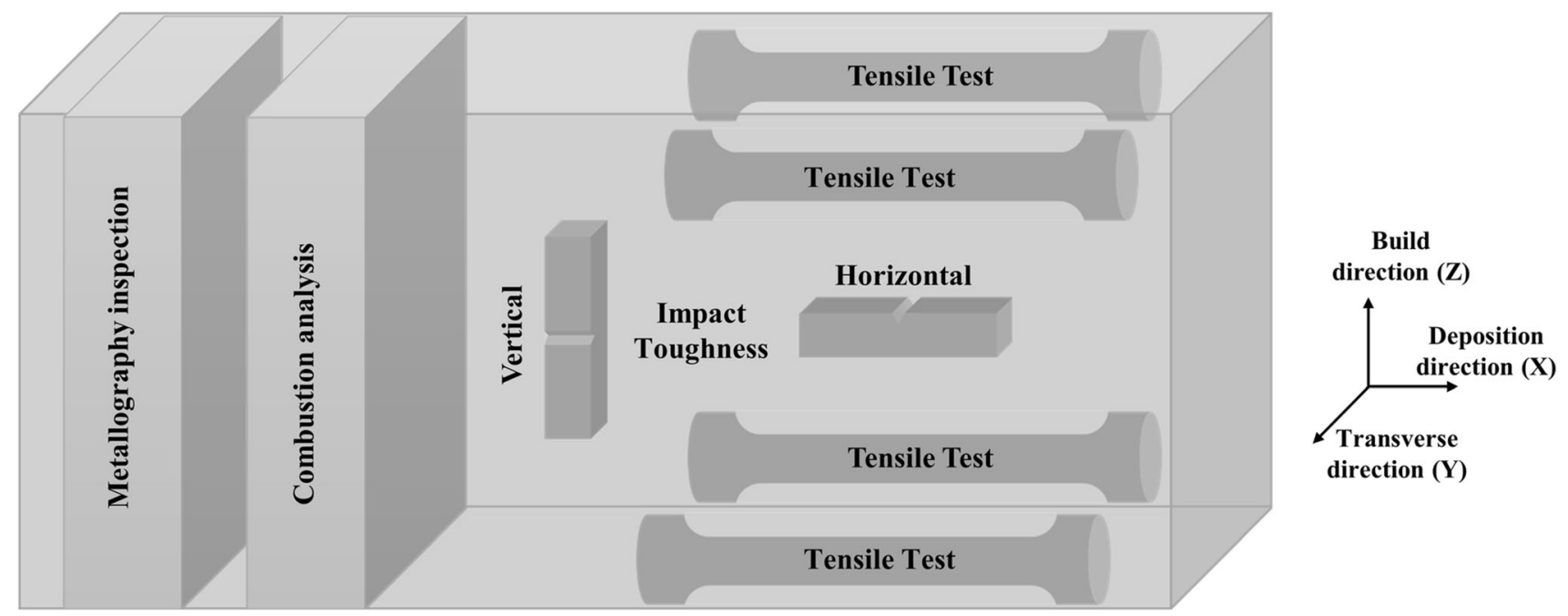

Figure 2 Extraction of specimens from the LMDw blocks and how they are orientated relative to the deposition and build directions. 


\section{Mechanical tests}

Tensile and Charpy impact toughness tests were performed on samples machined from the AD and HT blocks as shown in Fig. 2 and with dimensions as shown in Fig. 3. For the tensile tests, two specimens were extracted along the deposition direction from the bottom of the block and two from the top. The tensile tests were performed at room temperature according to EN ISO 6892-1. For investigation of impact toughness, samples from two different directions, along the deposition direction and the build direction, were prepared. The Charpy testing was done at $-10{ }^{\circ} \mathrm{C}$ according to EN ISO 148-1. For each direction, two tests were done.

\section{Results}

\section{Microstructure}

In this section, firstly an overview of the laser metal deposited blocks is presented. After that, the microstructures of both $\mathrm{AD}$ and HT conditions investigated using optical microscopy and EBSD analysis are presented. Finally, results of chemical analysis and mechanical testing reveal more details about the properties of the blocks produced by LMDw.

\section{Overview}

A representative macrograph from a cross section of one of the additive manufactured blocks is presented in Fig. 4. As it shows, 8 parallel beads were deposited in each layer, and thereafter, layers were added until the block was fabricated. In this macrograph etched with modified Beraha reagent, ferrite is the dark phase and austenite is the bright phase [29-31]. As can be seen, there was a periodic bead-to-bead microstructure in each layer. The deposition of layers upon each other, moreover, brought a repetitive microstructure consisting of largely ferritic and austenitic regions along the build direction. A few very small pores and possibly lack of fusion defects were found, particularly between the beads.

\section{As-deposited microstructure}

A schematic illustration and three-dimensional (3D) microstructures of LMDw block in AD condition are shown in Fig. 5, in which $X, Y$, and $Z$ are the deposition, transverse, and build directions, respectively. The 3D microstructure sections including the $X-Y, Y-$ $\mathrm{Z}$, and $\mathrm{X}-\mathrm{Z}$ planes indicate how LMDw resulted in an inhomogeneous and repetitive bead-to-bead and layer-to-layer microstructure.

The microstructures of the last deposited bead and the underlying beads reheated due to the deposition of the following beads are shown in Fig. 6a. As it can be seen, the deposition of each pass not only remelted a part of the previous layer but also heated the latest layers. The last bead has more ferrite, and reheated beads have more austenite. Higher magnification micrographs from the last deposited bead and the one-time reheated bead are displayed in Fig. $6 \mathrm{~b}$ and c, respectively. The last deposited bead, which is representative of the as-deposited DSS, had a largely ferritic microstructure, and the results of IA revealed that it had only $16 \pm 2 \%$ austenite. This austenite consists of intergranular (grain boundary), Widmanstätten, and intragranular austenite. The microstructure of the one-time reheated bead in Fig. $6 c$ shows that reheating derived from deposition of the subsequent bead alters the microstructure significantly and the austenite fraction increased up to $52 \pm 3 \%$. Compared to the as-deposited microstructure in Fig. $6 \mathrm{~b}$, after the first reheating cycle, the grain boundary and Widmanstätten austenite became thicker and the intragranular austenite grains coarsened. Formation of secondary (a)

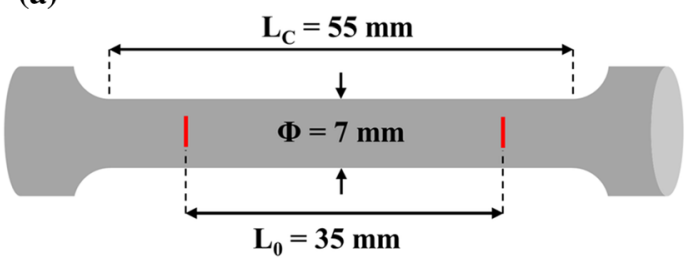

(b)

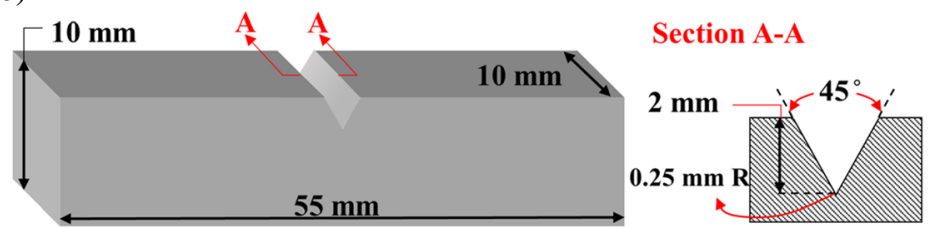

Figure 3 Test piece configuration of $\mathbf{a}$ tensile test and $\mathbf{b}$ Charpy impact test. 
Figure 4 Cross section of asdeposited laser metal deposited block including 8 passes in every 60 layers. The deposition of layers upon each other created a repetitive microstructure.
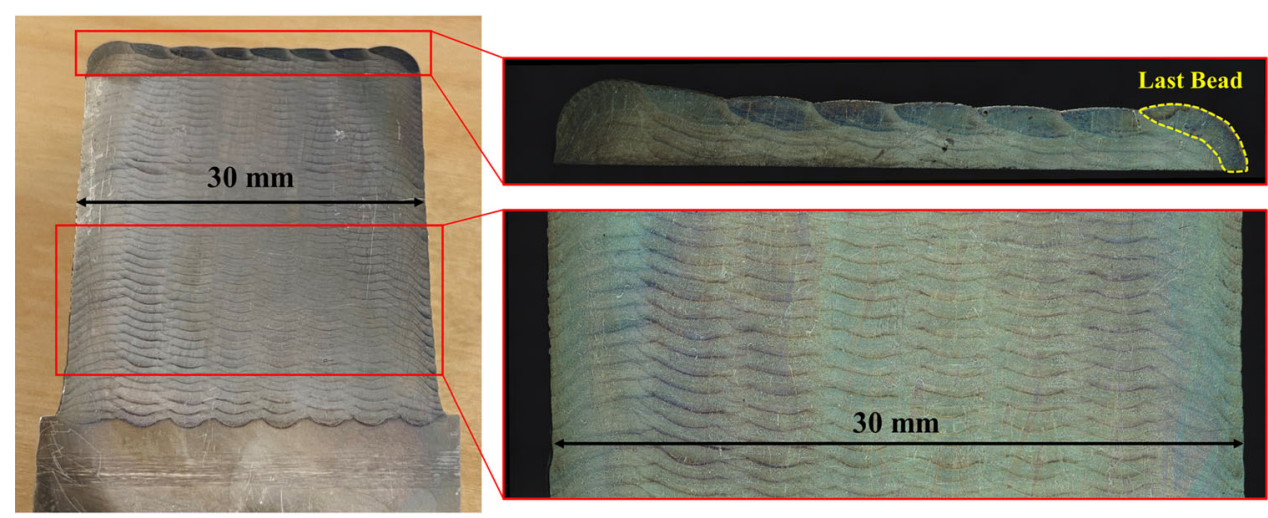

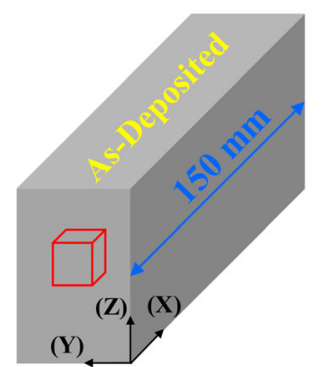

X: Deposition direction Y: Transverse direction Z: Build direction

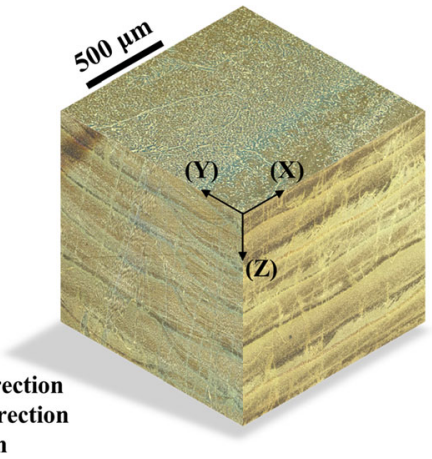

Figure 5 Schematic illustration and the 3D microstructures of laser metal deposited block in as-deposited conditions.

austenite, in addition, can be observed among the primary austenite.

Multiple reheating cycles make the microstructure even more complicated. The microstructure from the middle of the AD block which experienced several reheating cycles is shown in Fig. 7. It illustrates how the deposition of multiple beads produced an inhomogeneous and complex microstructure. The bottom rectangle in Fig. 7 shows a microstructure with of a small fraction of primary austenite and more than $70 \%$ secondary austenite clusters. The middle one demonstrates areas with a nearly fully ferritic microstructure. Surrounding these ferritic regions, there are various morphologies of austenite including primary intragranular and secondary austenite. Grain boundary austenite is also seen in the middle of this area which consists of two ferrite grains. Finally, the top rectangle includes both primary and secondary austenite with almost similar fractions in the ferrite matrix.

As can be seen in Fig. 7, there was a significant variation of ferrite and austenite fractions in the microstructure of the LMDw block. The locally unbalanced ferritic and austenitic microstructure was accompanied by the existence of very fine secondary austenite $(<1 \mu \mathrm{m})$ making IA less suitable for average phase fraction measurement. Ferrite number, therefore, was measured to estimate the ferrite content of the additively manufactured block. The average ferrite number of 10 measurements for in asdeposited condition was $55 \pm 3 \mathrm{FN}$.

The microstructure of the AD additive manufactured block after electrolytic etching with oxalic acid is presented in Fig. 8. Similar to the light optical micrograph etched with Beraha (Fig. 7), primary and secondary austenite can be observed in the ferritic matrix. Clusters of small black dots can also be seen in ferritic regions after etching with oxalic acid. These are due to, as has been demonstrated in numerous studies, local etching attack at nitrides in ferritic areas [26] and, therefore, show the presence of chromium nitrides [15, 16, 26, 32-34]. It can be noted that the nitrides preferentially formed in regions at some distance from austenite grains.

Results of EBSD analysis of the AD block are illustrated in Fig. 9. The EBSD phase map in Fig. 9a shows intergranular, Widmanstätten, and intragranular austenite, accompanied by the formation of very fine secondary austenite. The austenite fraction for the analyzed area was $32.2 \%$. Inverse pole figures (IPFs) of ferrite and austenite in AD condition are shown in Fig. $9 \mathrm{~b}$ and c, respectively. The ferritic band in the middle of the map indicates the boundary between two deposited beads. The same orientation of ferrite in the two beads confirms the epitaxial growth of solidifying ferrite in LMDw of DSS. As the ferrite grains are elongated in the build direction, grain boundary austenite, therefore, formed along this direction. Three ferrite grains can be seen with grains \#1 and \#2 having very similar 

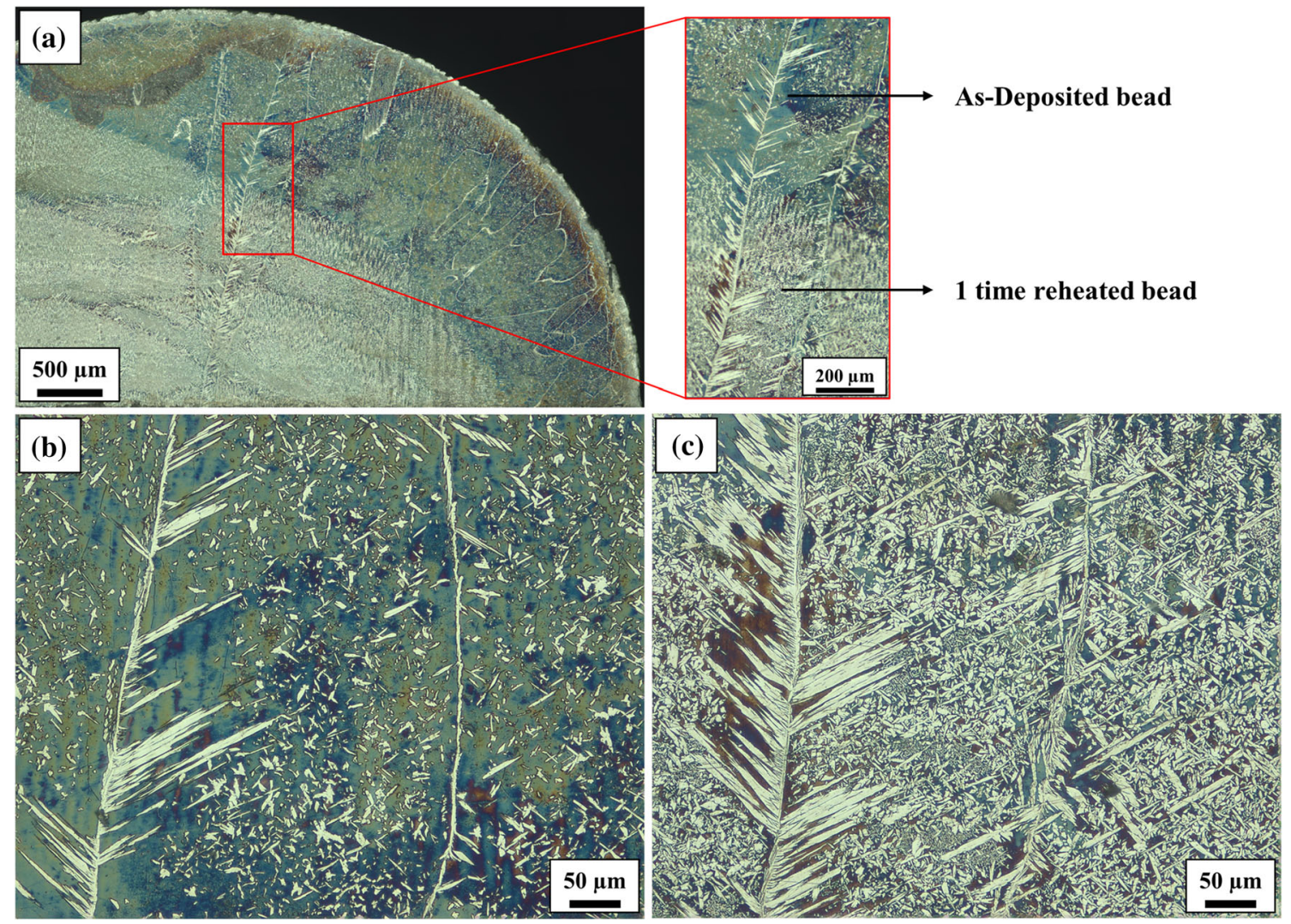

Figure 6 a The microstructure etched with modified Beraha and geometry of last deposited and underlying beads. The dark phase is ferrite, and the bright one is austenite. $\mathbf{b}$ Higher magnification of

orientations, while grain \#3 has a different orientation. From the black areas in the ferrite IPF, which are representative of austenite, it can be seen that there is much more grain boundary austenite between grains \#2 and \#3 than between \#1 and \#2.

\section{Heat-treated microstructure}

A schematic illustration and 3D microstructure of the LMDw block in HT condition are shown in Fig. 10. Sections for all the three $X-Y, Y-Z$, and $X-Z$ planes show a balanced microstructure and homogeneous distribution of ferrite and austenite after heat treatment. There is also no trace of a layer-by-layer microstructural variation as seen for the $\mathrm{AD}$ condition.

Micrographs showing the microstructure in a cross section of the block after heat treatment are presented in Fig. 11. In this microstructure, grain boundary, Widmanstätten, and intragranular austenite are seen in the ferrite matrix. Higher magnification micrographs of three regions reveal that the HT block

the microstructure in the last deposited bead, and $\mathrm{c}$ the one-time reheated bead.

contains a homogenized microstructure with an approximately balanced fraction of ferrite and austenite. Heat treatment resulted in the growth of austenite grains at both ferrite/ferrite boundaries and inside the ferrite grains. It, however, did not visibly change the morphology and structure of the ferrite grains, meaning that ferrite grains still have a textured structure along the build direction. Grain boundary austenite grains consequently also remained elongated along the build direction.

Due to the importance of phase balance in determining properties, the austenite fractions of 12 regions evenly distributed from the bottom to the top of the HT block were measured by IA and the result is presented in Table 3 . The results show that the average austenite fraction was $50.6 \pm 1.5$. The small variation of austenite fractions, in addition, implies a homogeneous microstructure through the build direction.

In addition to measurement with IA, the ferrite number was measured to permit comparison with 


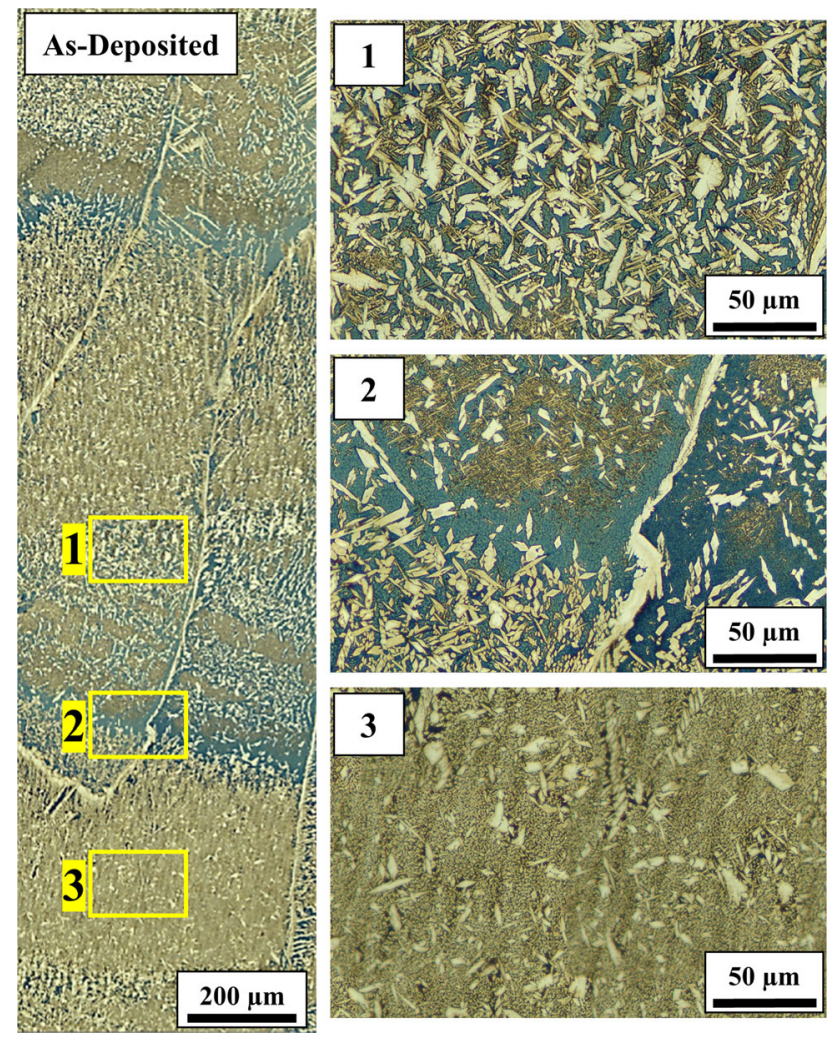

Figure 7 Inhomogeneous as-deposited microstructure including: (1) region with a large amount of secondary austenite, (2) a locally fully ferritic region, and (3) an area with a combination of primary and secondary austenite.

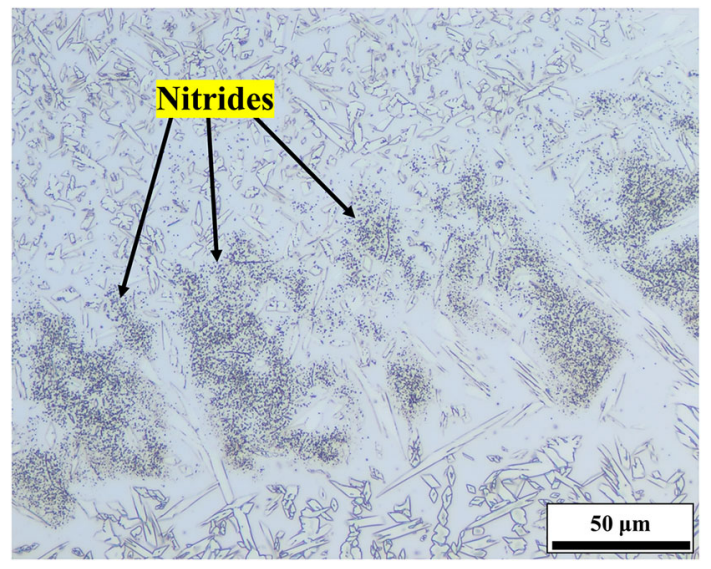

Figure 8 Microstructure of the AD block electrolytic etched with oxalic acid. Nitride formation can be seen in the ferritic areas.

the $\mathrm{AD}$ condition. The average ferrite number after heat treatment was $53 \pm 4 \mathrm{FN}$.

Results of EBSD analysis of the heat-treated block are presented in Fig. 12. As shown in the EBSD phase map in Fig. 12a, after heat treatment the austenite fraction was $53.7 \%$ for the studied area. The IPF map
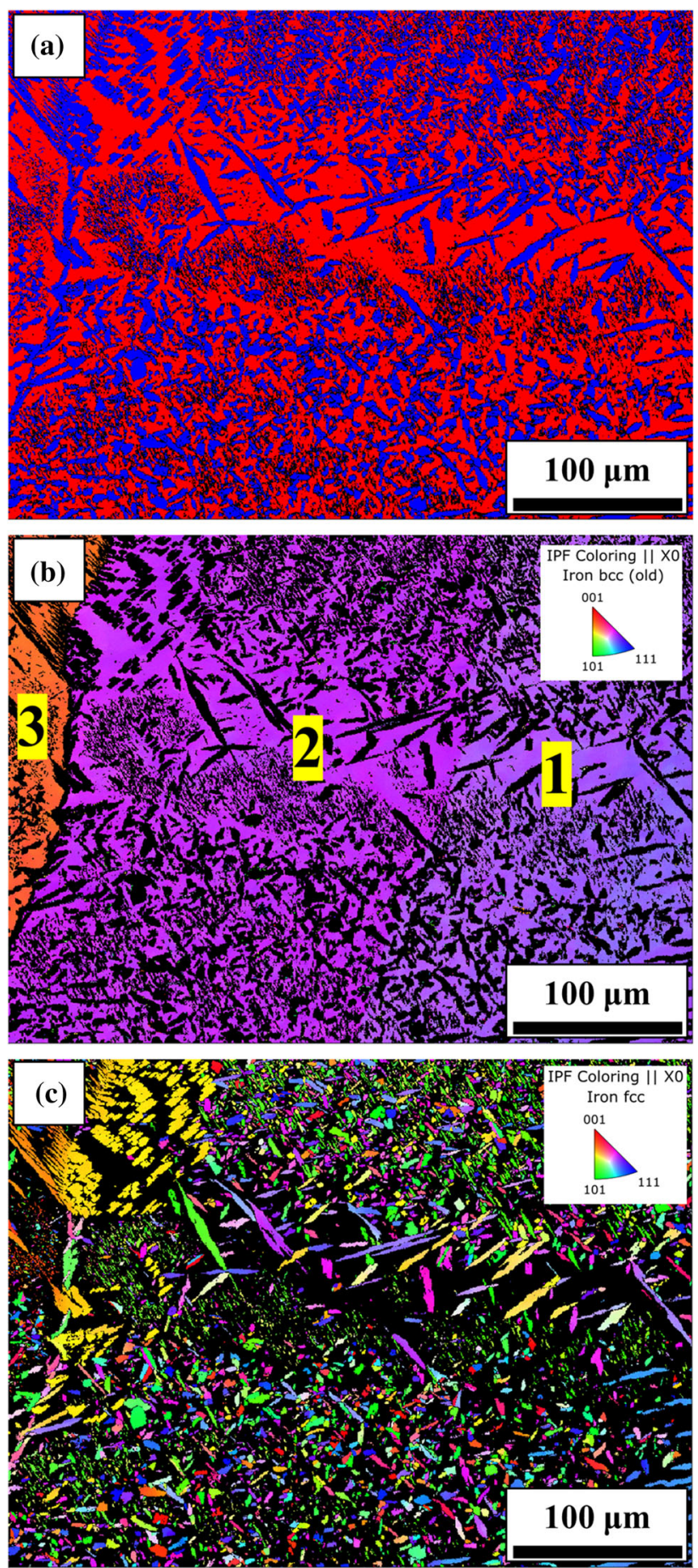

Figure 9 EBSD of a region in the center of the AD block. a Phase map showing ferrite in red and austenite as blue. The ferritic band in the middle of the map shows the location of the boundary between two layers. $\mathbf{b}$ IPF map of ferrite with three ferrite grains showing epitaxial growth from one layer into the next, and c IPF map of austenite showing primary grain boundary, Widmanstätten, intragranular, and secondary austenite. 


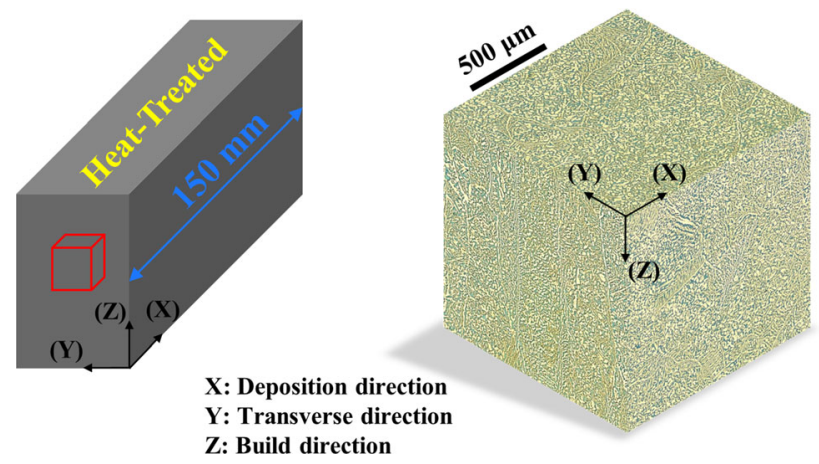

Figure 10 Schematic illustrations and the 3D microstructure of laser metal deposited block in the heat-treated condition. Heat treatment locally and globally balanced the fractions and the distributions of ferrite and austenite.

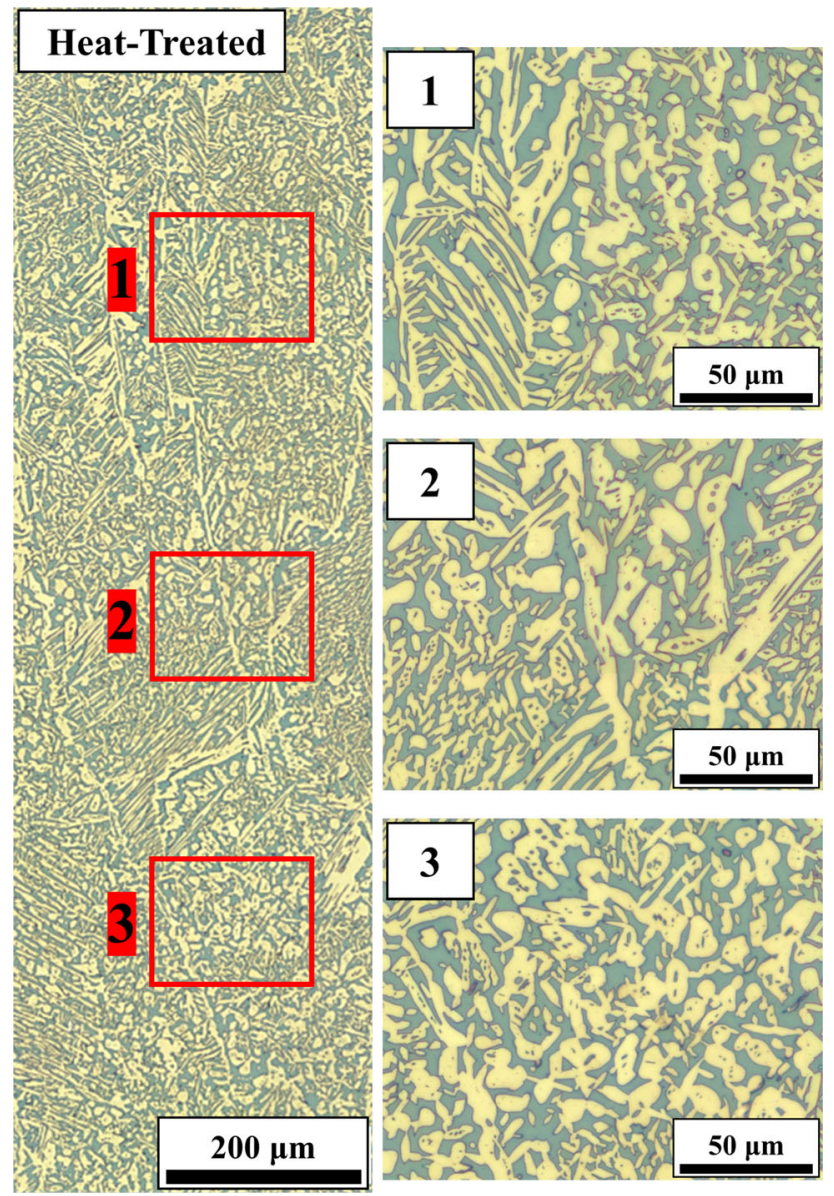

Figure 11 Heat treatment for $1 \mathrm{~h}$ at $1100{ }^{\circ} \mathrm{C}$ homogenized the microstructure and balanced the ferrite and austenite ratio. of ferrite in Fig. 12b shows two ferrite grains. As seen in the austenite IPF map, both austenite grains at ferrite/ferrite boundaries and inside ferrite grains grew during heat treatment.

\section{Chemical analysis}

As it is listed in Tables 4 and 5, the compositions did not vary from the bottom to the top of the blocks and were the same for AD and HT conditions. The OES and LECO analysis resulted in a very similar nitrogen content measurements and both indicate nitrogen loss in LMDw of DSS wire. Nitrogen content also did not change during subsequent heat treatment. LECO analysis, moreover, displays the oxygen contents were very low in both $\mathrm{AD}$ and HT blocks.

\section{Mechanical Properties}

The stress-strain curves of samples tested along the deposition direction of the AD and HT blocks are illustrated in Fig. 13, and the results are presented in Table 6. For both AD and HT conditions, the four specimens which were extracted from the bottom and top of the blocks demonstrate similar properties during the tensile tests. Yield strengths of AD samples were around $700 \mathrm{MPa}$ which decreased to approximately $500 \mathrm{MPA}$ after heat treatment. The ultimate tensile strength was reduced from near $850 \mathrm{MPa}$ in AD condition to about $750 \mathrm{MPa}$ in HT condition. On the contrary, the elongation increased from around $26 \%$ to near $34 \%$ after heat treatment.

Results of Charpy testing at $-10{ }^{\circ} \mathrm{C}$ for horizontal and vertical specimens are displayed in Fig. 14. It should be noted that for horizontal and vertical specimens, the notch was along the build and deposition directions (Fig. 2), respectively. In AD condition, the average impact toughness energy was $205 \mathrm{~J}$ for the horizontal samples, and $230 \mathrm{~J}$ for the vertical samples. After heat treatment, the impact toughness energy of the specimens reached averages of $239 \mathrm{~J}$ and $260 \mathrm{~J}$ in horizontal and vertical directions, respectively.

Table 3 Austenite content of additive manufactured block followed by $1 \mathrm{~h}$ heat treatment at $1100{ }^{\circ} \mathrm{C}$. Region \#1 was near the bottom, and region \#12 was close to the top of the block

\begin{tabular}{|c|c|c|c|c|c|c|c|c|c|c|c|c|c|}
\hline Region & 1 & 2 & 3 & 4 & 5 & 6 & 7 & 8 & 9 & 10 & 11 & 12 & Average \\
\hline Austenite fraction (\%) & 51 & 49 & 50 & 51 & 49 & 48 & 51 & 52 & 52 & 50 & 50 & 53 & $50.6 \pm 1.5$ \\
\hline
\end{tabular}



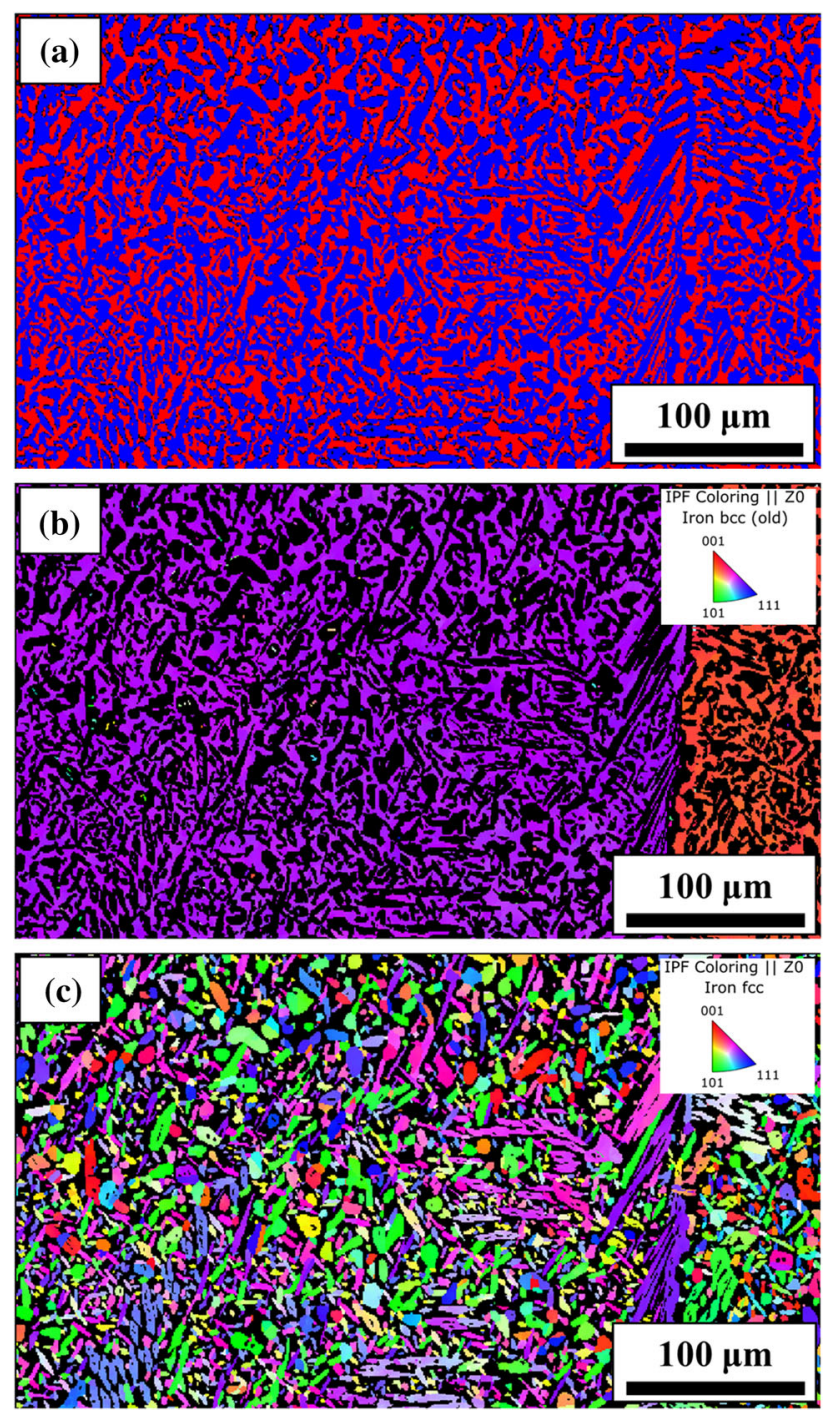

Figure 12 EBSD analysis of block in HT condition. a Phase map displaying ferrite and austenite in red and blue, respectively. IPF coloring maps of $\mathbf{b}$ ferrite, and $\mathbf{c}$ austenite. Austenite grains grew during heat treatment.
Table 5 Nitrogen and oxygen measurement by combustion analysis using a LECO TC-436 analyzer

\begin{tabular}{llll}
\hline & & Nitrogen (wt.\%) & Oxygen (ppm) \\
\hline As-deposited & Bottom & 0.12 & 62 \\
& Middle & 0.11 & 54 \\
& Top & 0.11 & 61 \\
Heat-treated & Bottom & 0.12 & 76 \\
& Middle & 0.12 & 68 \\
& Top & 0.11 & 73 \\
\hline
\end{tabular}

\section{Fractography}

Cross sections of the fracture surface of the horizontal and vertical specimens for Charpy testing in AD and HT conditions are illustrated in Fig. 15. In horizontal samples, there were several deposited layers along the path of the crack growth, while in the vertical samples, the crack growth path was in one or two layers. After heat treatment, as indicated in Fig. 15d, the ferrite grains and grains boundary austenite grains were still elongated along the build direction. It can be seen that, in vertical samples in both $\mathrm{AD}$ and HT conditions, the crack was changing its direction when it met grain boundary austenite.

\section{Sensitized microstructure}

Micrographs showing microstructures of additive manufactured blocks after electrolytic etching with oxalic acid to reveal sensitization are displayed in Fig. 16. The microstructure for the $\mathrm{AD}$ condition in Fig. 16a illustrates the boundary region of two deposited layers. This microstructure in more heavily

Table 4 Chemical composition analysis of the AD and HT blocks by optical emission spectroscopy (OES)

\begin{tabular}{lllllllllllll}
\hline & & $\mathrm{C}$ & $\mathrm{Si}$ & $\mathrm{Mn}$ & $\mathrm{P}$ & $\mathrm{S}$ & $\mathrm{Cr}$ & $\mathrm{Ni}$ & $\mathrm{Mo}$ & $\mathrm{N}$ & $\mathrm{Cu}$ & $\mathrm{V}$ \\
\hline As-Deposited & Top & 0.025 & 0.45 & 1.47 & 0.017 & 0.002 & 23.15 & 8.49 & 3.19 & 0.11 & 0.04 & 0.08 \\
& Middle & 0.022 & 0.45 & 1.46 & 0.016 & 0.002 & 23.13 & 8.47 & 3.18 & 0.11 & 0.04 & 0.08 \\
& Bottom & 0.023 & 0.45 & 1.47 & 0.017 & 0.002 & 23.15 & 8.49 & 3.19 & 0.11 & 0.04 & 0.08 \\
Heat-treated & Top & 0.023 & 0.45 & 1.47 & 0.016 & 0.002 & 23.23 & 8.48 & 3.17 & 0.11 & 0.04 & 0.08 \\
& Middle & 0.022 & 0.45 & 1.46 & 0.016 & 0.002 & 23.22 & 8.48 & 3.17 & 0.10 & 0.04 & 0.08 \\
& Bottom & 0.024 & 0.45 & 1.47 & 0.016 & 0.002 & 23.23 & 8.48 & 3.17 & 0.11 & 0.04 & 0.08 \\
\hline
\end{tabular}



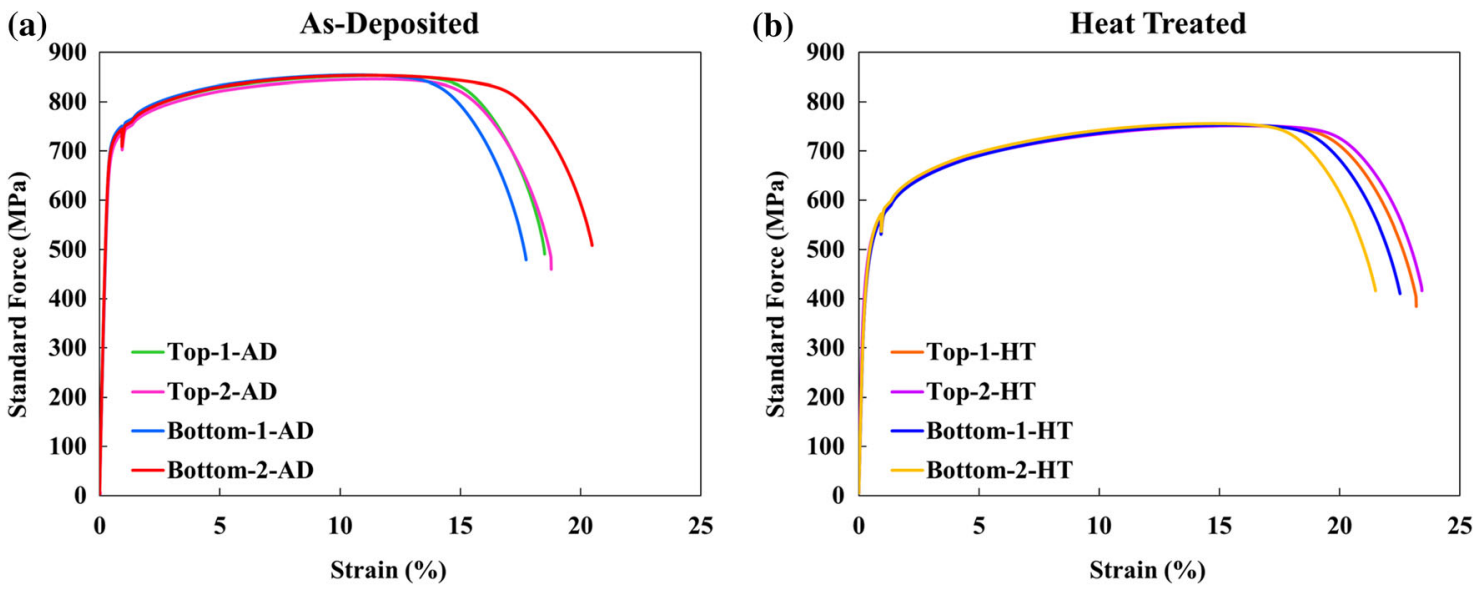

Figure 13 Stress-strain curves of DSS block in the as-deposited and heat-treated condition.

Table 6 Tensile test results

\begin{tabular}{llllll}
\hline & & & Yield strength $(\mathrm{MPa})$ & Ultimate tensile strength (MPa) & $\mathrm{A}_{5}(\%)$ \\
\hline \multirow{2}{*}{ As-deposited } & \multirow{2}{*}{ Top } & S1 & 705 & 853 & 25.2 \\
& & S2 & 697 & 846 & 26.5 \\
& \multirow{4}{*}{ Bottom } & S1 & 722 & 854 & 25.5 \\
& & S2 & 702 & 853 & 28.0 \\
& \multirow{4}{*}{ Top } & S1 & 481 & 751 & 35.2 \\
& \multirow{3}{*}{ Bottom } & S2 & 489 & 752 & 34.7 \\
& & S1 & 486 & 753 & 34.1 \\
& S2 & 493 & 756 & 32.6 \\
\hline
\end{tabular}

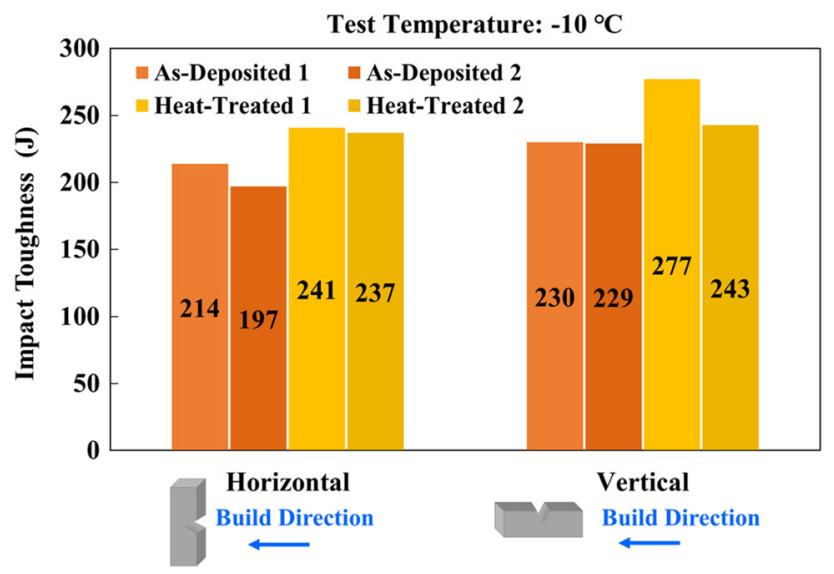

Figure 14 The Charpy impact toughness energy of horizontal and vertical specimens from AD and HT blocks.

etched regions is expected to be more susceptible to local corrosion attack. Higher magnification micrographs in Fig. $16 \mathrm{~b}$ and $\mathrm{c}$ indicate that the regions containing nitrides and/or secondary austenite clusters are the most sensitized areas. In HT condition as shown in Fig. 16d, however, there were no indications of sensitization.

\section{Thermodynamic calculations}

Comparing the nitrogen content of the feedstock wire from Table 1 and the produced AM blocks according to Tables 4 and 5 revealed nitrogen loss during LMDw. To understand the effect of nitrogen loss, the equilibrium phase diagrams for the feedstock wire, according to its chemical composition from wire certificate and nitrogen content of $0.16 \%$, and the block based on the OES analysis with the nitrogen content of $0.11 \%$ were calculated by Thermo-Calc (Fig. 17). Nitrogen loss influenced phase transformation and delayed solid-state transformation of ferrite to austenite.

\section{Discussion}

With the implementation of LMDw combined with the hot-wire technology, it was possible to successfully fabricate two high-quality DSS blocks with the dimensions of $150 \times 70 \times 30 \mathrm{~mm}^{3}$. These were investigated in as-deposited and heat-treated conditions. 

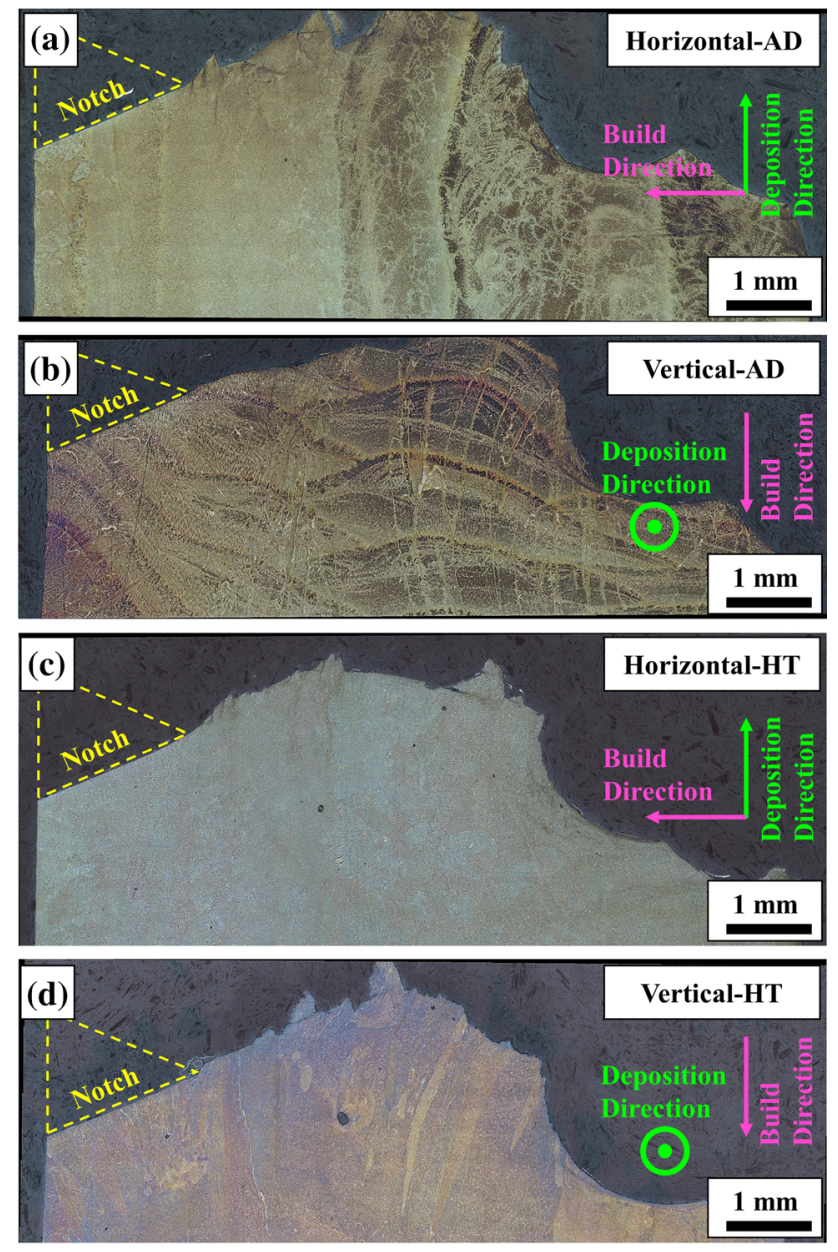

Figure 15 Cross sections of Charpy test specimens with notch along or perpendicular to the deposition direction. In vertical samples, the crack path changed at grain boundary austenite.

The results showed that the blocks had promising properties in both AD and HT conditions.

In this section, the microstructures of $\mathrm{AD}$ and $\mathrm{HT}$ specimens are evaluated based on results of light optical microscopy and EBSD analysis. Thereafter, the relation between the mechanical properties and microstructures is discussed, and a mechanism explaining the different mechanical behavior of samples oriented along the deposition and build directions is proposed.

\section{Chemical composition}

The negligible variation of composition from the bottom to the top of the blocks represents a stable LMDw process. A comparison of OES analysis of the blocks (Table 4) and the wire chemical composition (Table 1) shows that most of the element's contents were virtually unchanged. The nitrogen content, however, decreased to around $0.11 \%$ during manufacturing of the blocks as was confirmed by LECO analysis (Table 7). Nitrogen loss has been observed in previous studies on AM of DSS [20,35]. The approximately $0.05 \%$ nitrogen loss in manufacturing of the block in this research was similar to the near $0.04 \%$ nitrogen loss in the initial stage of this study on single-bead wall production by LMDw [4].

Nitrogen loss affects the phase transformation and subsequently phase balance in DSS. As shown in Fig. 17, nitrogen loss postpones ferrite-to-austenite transformation to lower temperatures. Nitrogen content, therefore, is of significant importance in balancing ferrite and austenite ratio in AM of DSS. Despite the nitrogen loss in this research, the resulting nitrogen level in combination with the wire nickel content of $8.6 \%$ was adequate to form sufficient amounts of austenite to achieve good properties. This combination of nickel and nitrogen was also well suited for heat treatment which produced a balanced microstructure. However, other studies revealed that nitrogen loss combined with the lower nickel content, $5-6 \%$, resulted in a ferritic microstructure of the asbuilt additively manufactured parts [18, 19] and even a subsequent heat treatment could not bring a balanced microstructure.

\section{As-deposited microstructure}

In addition to nitrogen loss, the high cooling rate of LMDw restricts austenite formation during the deposition of DSS [4]. Duplex stainless steels solidify fully ferritic, and as the temperature decreases, ferrite partly transforms to austenite. The austenite first forms at ferrite-ferrite grain boundaries as intergranular, also called grain boundary, austenite, and then as the driving force increases also inside the ferrite grains as intragranular and Widmanstätten austenite [11, 12]. This solid-state ferrite-to-austenite transformation is controlled by the diffusion of alloying elements, particularly nitrogen [16]. Therefore, the high cooling rate of LMDw suppressed sufficient diffusion and subsequently austenite formation, as indicated in the microstructure of the last deposited bead in Fig. 6. Due to the rapid cooling, ferrite became supersaturated in nitrogen and nitrides formed in highly ferritic regions [26] on cooling and reheating (Fig. 8). 

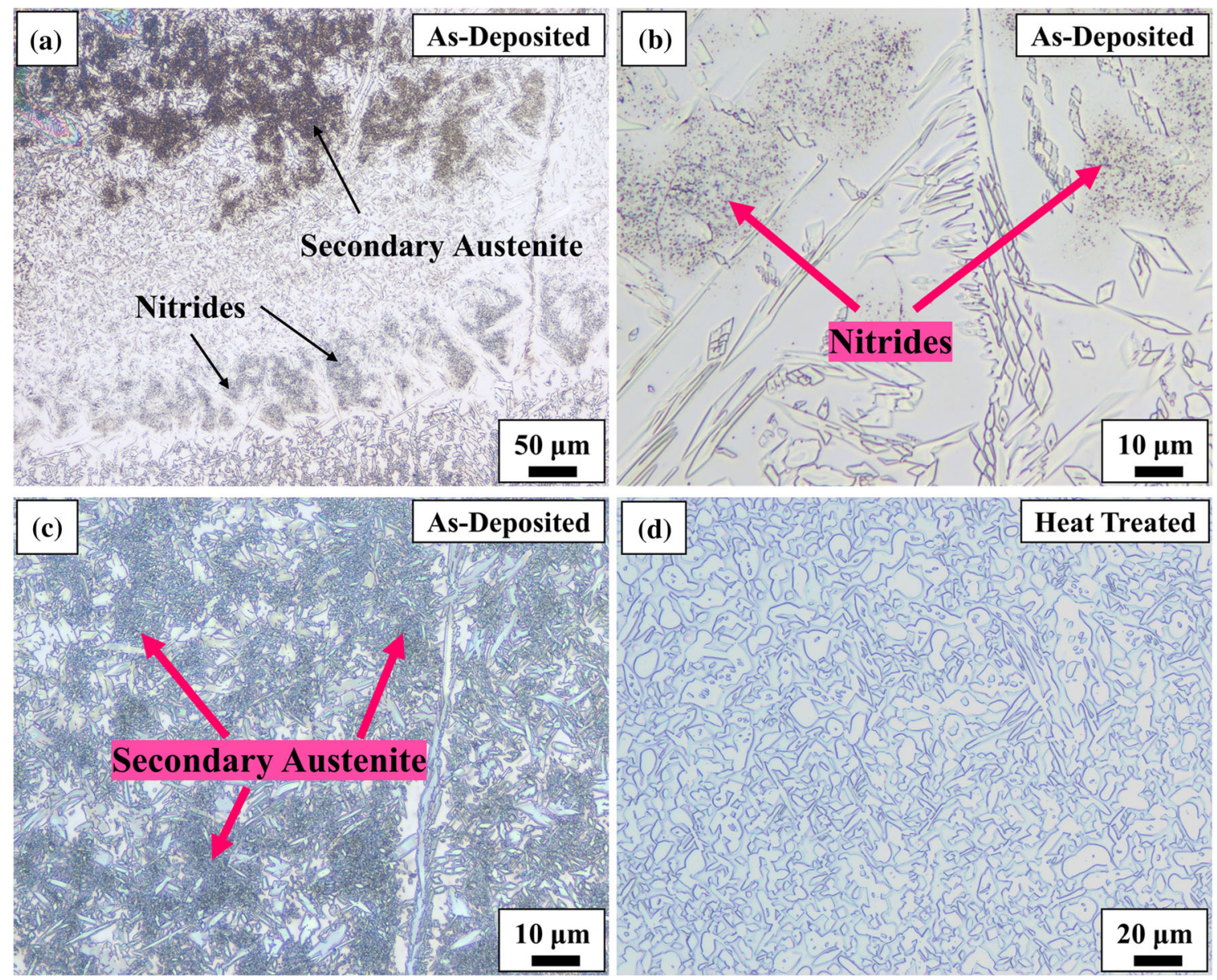

Figure 16 a Microstructure of as-deposited block after etching with oxalic acid to reveal sensitization. $\mathbf{b}$ Heavy etching at nitrides suggesting sensitization. c Etching attacks at secondary austenite

As it is illustrated in Fig. 18, during the deposition of two layers of DSS, the second bead will cause the formation of a heat-affected zone (HAZ) in the first bead. Therefore, depending on their distance to the fusion line, different regions experiencing various thermal cycles are created. The region adjacent to the new deposited bead is the high-temperature heataffected zone (HTHAZ) with a high ferrite fraction and nitride formation [36] which deteriorates the corrosion resistance of DSS [26, 32]. The second one is the low-temperature heat-affected zone (LTHAZ) that experienced lower peak temperatures where secondary austenite clusters can form. And finally, there is an "unaffected area" in which the combination of time and temperature was not sufficient to cause any phase transformation. As shown in Fig. 6, one additional reheating and cooling cycle played a crucial role in promoting austenite formation since it provided sufficient time at elevated temperatures for

clusters. d Microstructure of heat-treated condition without any indication of sensitization.

nitrogen diffusion and austenite formation. In the one-time reheated bead, the austenite fraction increased around $36 \%$. This was the result of the growth of primary grain boundary, Widmanstätten, and intragranular austenite accompanied by the formation of secondary austenite [37-39].

In the bulk of AM components, the deposition of the following beads makes the total experienced thermal cycles very complicated [20, 31, 40]. Therefore, as illustrated in Fig. 7, the bulk of the laser metal deposited blocks show a complex and inhomogeneous microstructure but is at the same time periodically repetitive.

In this study, FERITESCOPE measurements showed an average ferrite number of $55 \pm 3 \mathrm{FN}$ for the bulk of the block in AD condition. This is well within the range of 30-90 FN often considered as acceptable for DSS welds [41]. 
The AD microstructure after etching with oxalic acid in Fig. 16 revealed that regions with nitrides and secondary austenite clusters can be expected to be vulnerable to corrosion attack. For nitrides, localized corrosion has been reported as a consequence of chromium depletion around the nitrides inside the ferrite grains [26, 32]. Secondary austenite clusters, as Hosseini et al. [42] showed based on thermodynamic calculations, are sensitive against localized corrosion as the consequence of having lower contents of chromium, molybdenum, and nitrogen.

Another phenomenon in the LMDw of DSS, as in multipass welding, is the epitaxial growth of ferrite grains along the build direction. As displayed in Fig. 9, during deposition of a new bead/layer, as the

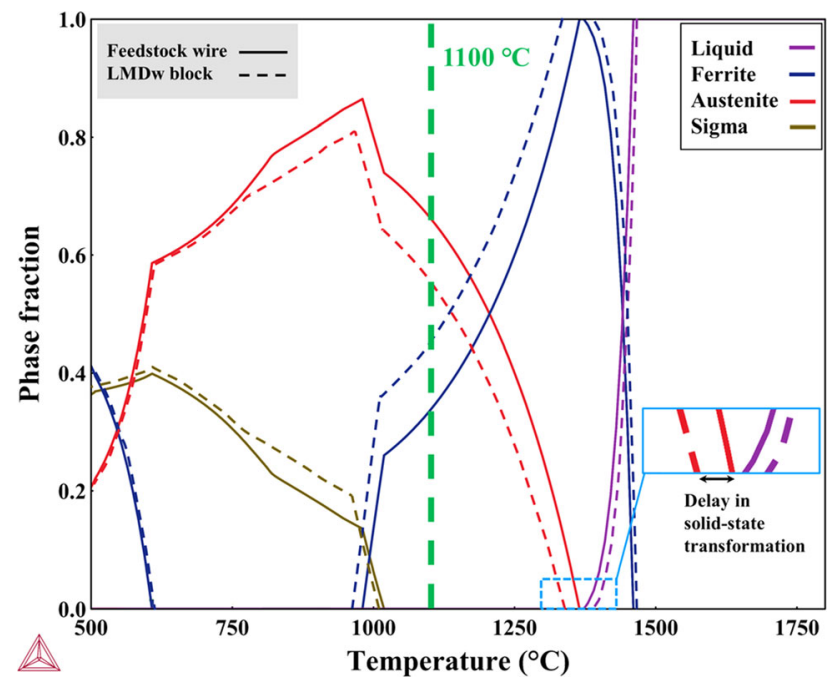

Figure 17 Phase diagram calculated with Thermo-Calc for the nitrogen contents of feedstock wire $(0.16 \%)$ and LMDw blocks (0.11). An approximately balanced fractions of ferrite and austenite can be seen at the heat treatment temperature of $1100{ }^{\circ} \mathrm{C}$. energy to nucleate new grains during solidification is larger than the energy required for the growth of the fusion boundary grains, epitaxial growth happens. As the temperature gradient is along the build direction, the solidifying ferrite grains preferentially grow along this direction. After solidification of ferrite, austenite forms either at ferrite/ferrite grain boundaries or inside ferrite grains. The grain boundary austenite is, therefore, also mainly oriented along the build direction which will be discussed in Sect. Mechanical properties.

\section{Heat-treated microstructure}

Heat treatment homogenized the microstructure and balanced the ferrite and austenite fractions in entire the block with an average austenite fraction of around $51 \%$ (Table 3). Heat treatment, moreover, dissolved nitrides.

Heat treatment coarsened the grain boundary and Widmanstätten, and particularly intragranular austenite. In addition to the growth, intragranular austenite had a globular morphology, contrary to the angular shape in AD material, as has been reported in heat-treated duplex and super duplex stainless steel $[25,43]$. This behavior was also observed in the heat treatment of the LMDw single-bead wall, and it can be attributed to reducing the total interface energy in austenite-ferrite boundaries [4]. Heat treatment and the resulting globular and homogeneous microstructure could also be expected to decrease the residual stresses introduced by LMDw [18].

The morphology and size of the ferrite grains did not change significantly. According to the equilibrium phase diagram (Fig. 17), there was still some

Table 7 Nitrogen content (wt.\%) of the laser metal deposited blocks in $\mathrm{AD}$ and HT conditions determined with OES and combustion analysis

\begin{tabular}{lllllll}
\hline & \multicolumn{2}{l}{ As-deposited } & & & \multicolumn{2}{l}{ Heat-treated } \\
\cline { 2 - 3 } & Bottom & Top & & Bottom & Top \\
\hline Optical emission spectroscopy (OES) & 0.11 & 0.11 & & 0.11 & 0.11 \\
Combustion analysis by LECO analyzer & 0.12 & 0.11 & & 0.12 & 0.11 \\
Wire composition according to the certificate & 0.16 & & & \\
\hline
\end{tabular}

(a)

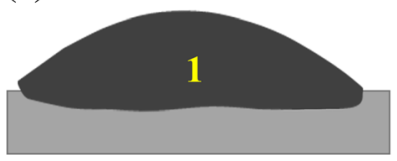

(b)

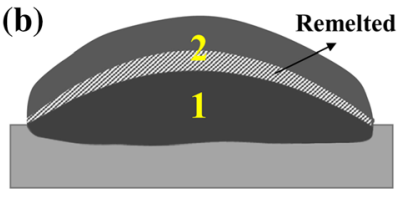

(c)

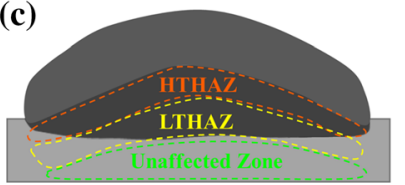

Figure 18 Schematic illustration for deposition of layers upon each other and how it creates various microstructural zones. 
content of austenite at heat treatment temperature of $1100{ }^{\circ} \mathrm{C}$. The undissolved austenite grains were particularly at the ferrite-ferrite grain boundaries due to their larger size. The ferrite grains as well as grain boundary austenite, therefore, were not largely affected by the heat treatment and preserved their texture and orientation.

\section{Mechanical properties}

In tensile testing, in both $\mathrm{AD}$ and $\mathrm{HT}$ conditions, the similar behavior of the specimens extracted from different depths demonstrates the isotropy of tensile properties along the deposition direction through the build direction. In the AD condition, the microstructure was, as discussed in 4.2, not homogeneous due to the layer-upon-layer nature of LMDw. However, as the variation is systematic and repetitive throughout the material from the bottom to the top of the block, it resulted in the same tensile properties. In addition, the average value for yield strength of asdeposited block was around $700 \mathrm{MPa}$, which was comparable to the average strength of $717 \mathrm{MPa}$ reported in cold metal transfer additive manufacturing with 2209 types of DSS wire [22]. In HT samples, the homogeneous microstructure brought as expected similar tensile properties from the bottom to the top of the block with lower strength and higher ductility compared to AD.

Strength and toughness were on a high level both as-deposited and after heat treatment, comparable to or above requirements in standards for wrought type 2205 duplex stainless steel. The yield strength was between 697 and $722 \mathrm{MPa}$ in as-deposited condition and from 481 to $493 \mathrm{MPa}$ after heat treatment which is above the minimum requirement of $480 \mathrm{MPa}$ for wrought type 2205 DSS [44]. The tensile strength was within the range of standard requirements for 2205 DSS [44], i.e., 700-920 MPa, both as-deposited with 846-854 MPa and heat-treated with 751-756 MPa. The elongation was also more than $25 \%$, which is the minimum required value of wrought type 2205 duplex stainless steel, in both as-deposited condition and after heat treatment. The impact toughness energy was comparable to the $230 \mathrm{~J}$ typical for 2205 DSS [45]. However, samples with the notch perpendicular to the build direction had higher impact toughness energies (229-277 J) compared to samples with the notch parallel to the build direction (197-241 J).
In Charpy testing, the impact toughness energies of both vertical and horizontal specimens demonstrated high levels of impact toughness energy in both $\mathrm{AD}$ or HT blocks. Oxygen content largely governs the amount of micro-slag inclusions and thereby has a major effect on the ductility and the impact toughness energy of the additive manufactured components. The low contents of oxygen, between 50 and $80 \mathrm{ppm}$, therefore ensured a high ductility and toughness energy in the LMDw of DSS blocks. Furthermore, heat treatment increased impact toughness. This was owing to the homogenizing of the microstructure and the removal of nitrides.

Another interesting observation was that the vertical specimens with the notch along the deposition direction had higher impact toughness energy than the horizontal specimens in which the notch was perpendicular to the deposition direction both $\mathrm{AD}$ and after HT (Fig. 14). In Charpy testing, the crack grows from the tip of the notch and it preferentially propagates through the ferrite due to its lower ductility and toughness [46]. According to the micrographs showing cross sections of the notch region in Fig. 9 and the schematic illustrations in Fig. 19, in vertical samples, the grain boundary austenite acts as a barrier for the crack growth. A higher magnification micrograph of the vertical specimen cross section in Fig. 19 reveals that the crack changed its growth direction to avoid the grain boundary austenite. Therefore, as the crack was forced to first change direction and finally to pass the tougher grain boundary austenite, more energy was required which resulted in a higher total impact toughness energy. In horizontal samples, however, there were fewer austenite barriers to the crack growth, and the toughness was lower. As explained in the previous section, the grain boundary austenite was not eliminated during heat treatment and preserved its shape and orientation along the build direction. It, therefore, could act as a barrier to crack growth even after heat treatment. The same behavior in the HT samples provided evidence for the increment of the impact toughness energy for specimens with the notch along the deposition direction.

The reduction of yield and tensile strength and the increment of ductility after heat treatment are completely in agreement with the result of Paoula et al. [18]. In their study, additively manufactured 2205 DSS samples had a yield strength of $950 \mathrm{MPa}$ and a tensile strength of $1071 \mathrm{MPa}$. Heat treatment for 


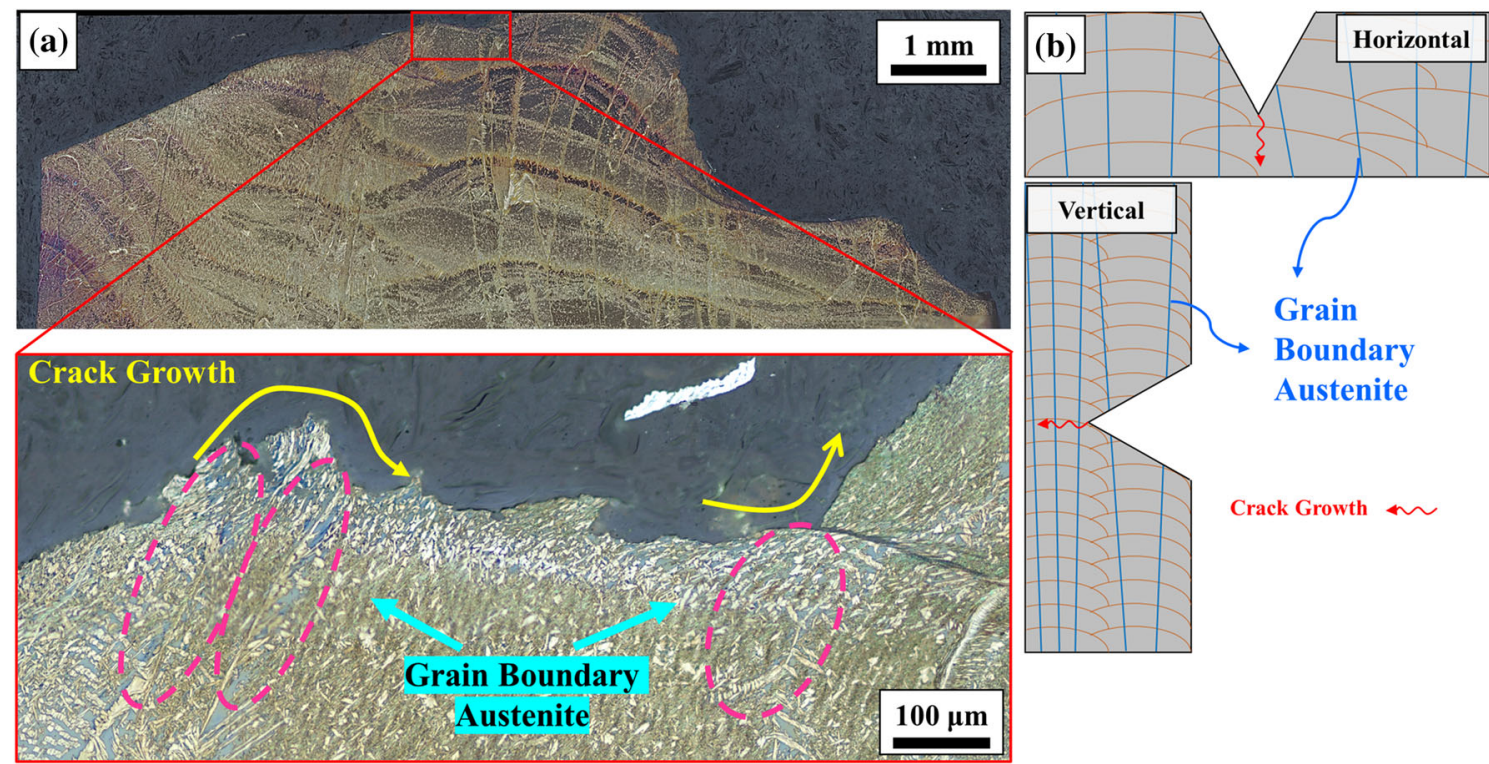

Figure 19 a Cross section of the notch region of a vertical Charpy test specimen. The crack rounded the grain boundary austenite to grow. b Schematic illustration of crack growth path relative to the grain boundary austenite in the horizontal and vertical Charpy test specimens.

$5 \mathrm{~min}$ at $1100{ }^{\circ} \mathrm{C}$, however, reduced these values to $524 \mathrm{MPa}$ and $824 \mathrm{MPa}$, respectively. The elongation, on the contrary, increased from 7 to $24 \%$ after heat treatment.

The results of this study provide evidence that components fabricated with LMDw can to a larger or smaller degree have anisotropic properties both in $\mathrm{AD}$ and HT conditions. This is in line with the results of Lervåg et al. [23] in the investigation on AM of super DSS. They observed higher tensile strength along the deposition directions in comparison with the build direction. The additively manufactured blocks in this study nevertheless had similar properties regardless of the location of the samples through the build direction. Future studies are, however, required to further explore this promising finding.

\section{Conclusions}

Two high-quality duplex stainless steel blocks $\left(150 \times 70 \times 30 \mathrm{~mm}^{3}\right)$ were successfully produced by additive manufacturing using the LMDw process and were studied in as-deposited and heat-treated conditions. Analysis of chemical composition, microstructure characterization, and mechanical testing demonstrated how the LMDw and subsequent heat treatment affect the microstructures and performance.

1. A stable and consistent LMDw process enabled the successful production of high-quality, virtually defect-free DSS blocks.

2. The as-deposited microstructure was inhomogeneous and repetitive including ferritic areas with nitrides and austenitic regions with fine secondary austenite.

3. Heat treatment locally and globally homogenized the microstructure, removed nitrides, and balanced the ferrite and austenite fractions.

4. Epitaxial growth of ferrite grains resulted in a textured microstructure along the build direction, which remained after heat treatment.

5. About $0.05 \%$ nitrogen was lost during LMDw resulting in a level of about $0.11 \%$. This level in combination with the relatively high nickel content was adequate to form close to $50 \%$ austenite both in as-deposited condition, due to multiple reheating by subsequent passes, and during heat treatment.

6. Mechanical properties fulfilled common requirements on strength and toughness in both asdeposited and heat-treated conditions.

7. Heat treatment decreased yield strength from about $750 \mathrm{MPa}$ to about $450 \mathrm{MPa}$ and tensile strength from 850 to $750 \mathrm{MPa}$, while impact toughness was in all cases close to or above $200 \mathrm{~J}$. 
8. Impact toughness testing with the notch transverse to the build direction resulted in higher impact toughness energies in both AD and HT conditions as grain boundary austenite acted as a barrier to crack growth.

\section{Acknowledgements}

This research project was supported by grants from the Swedish Knowledge Foundation project SAMw [20170060].

\section{Funding}

Open access funding provided by University West.

\section{Declarations}

Conflict of interest The authors declared that they have no conflict of interest.

Open Access This article is licensed under a Creative Commons Attribution 4.0 International License, which permits use, sharing, adaptation, distribution and reproduction in any medium or format, as long as you give appropriate credit to the original author(s) and the source, provide a link to the Creative Commons licence, and indicate if changes were made. The images or other third party material in this article are included in the article's Creative Commons licence, unless indicated otherwise in a credit line to the material. If material is not included in the article's Creative Commons licence and your intended use is not permitted by statutory regulation or exceeds the permitted use, you will need to obtain permission directly from the copyright holder. To view a copy of this licence, visit http://creativecommons.org/licen ses/by/4.0/.

\section{References}

[1] Maleki E, Bagherifard S, Bandini M, Guagliano M (2021) Surface post-treatments for metal additive manufacturing: progress, challenges, and opportunities. Addit Manuf 37:101619. https://doi.org/10.1016/j.addma.2020.101619

[2] DebRoy T, Wei HL, Zuback JS et al (2018) Additive manufacturing of metallic components - process, structure and properties. Prog Mater Sci 92:112-224. https://doi.org/10. 1016/j.pmatsci.2017.10.001

[3] ASTM (2012) Standard terminology for additive manufacturing technologies; F2792-12a; ASTM international: West Conshohocken, PA. USA 63:4-11

[4] Valiente Bermejo MA, Thalavai Pandian K, Axelsson B et al (2021) Microstructure of laser metal deposited duplex stainless steel: influence of shielding gas and heat treatment. Weld World 65:525-541. https://doi.org/10.1007/s40194-02 0-01036-5

[5] Kisielewicz A, Thalavai Pandian K, Sthen D et al (2021) Hot-wire laser-directed energy deposition: process characteristics and benefits of resistive pre-heating of the feedstock wire. Metals (Basel) 11:634. https://doi.org/10.3390/me t11040634

[6] Ivántabernero PA, Álvarez P, Suárez A (2018) Study on arc welding processes for high deposition rate additive manufacturing. Procedia CIRP 68:358-362. https://doi.org/10.10 16/j.procir.2017.12.095

[7] Frazier WE (2014) Metal additive manufacturing: a review. J Mater Eng Perform 23:1917-1928. https://doi.org/10.1007/ s11665-014-0958-Z

[8] Gu DD, Meiners W, Wissenbach K, Poprawe R (2012) Laser additive manufacturing of metallic components: materials, processes and mechanisms. Int Mater Rev 57:133-164. h ttps://doi.org/10.1179/1743280411Y.0000000014

[9] Saeidi K, Kevetkova L, Lofaj F, Shen Z (2016) Novel ferritic stainless steel formed by laser melting from duplex stainless steel powder with advanced mechanical properties and high ductility. Mater Sci Eng A 665:59-65. https://doi.org/10.10 16/j.msea.2016.04.027

[10] Wu HC, Tsay LW, Chen C (2004) Laser beam welding of 2205 duplex stainless steel with metal powder additions. ISIJ Int 44:1720-1726. https://doi.org/10.2355/isijinternational.4 4.1720

[11] Lippold JC, Kotecki DJ, Sant S (2006) Welding metallurgy and weldability of stainless steels. MRS Bull Res Soc 31:58

[12] Zhang $\mathrm{Z}$, Jing $\mathrm{H}$, $\mathrm{Xu} \mathrm{L}$ et al (2016) Investigation on microstructure evolution and properties of duplex stainless steel joint multi-pass welded by using different methods. Mater Des 109:670-685. https://doi.org/10.1016/j.matdes.2 016.07 .110

[13] Karlsson L, Arcini H (2012) Low energy input welding of duplex stainless steels. Weld World 56:41-47

[14] Karlsson L (2012) Welding duplex stainless steels - a review of current recommendations. Weld World 56:65-76. https://d oi.org/10.5937/zzk1802065k

[15] Hosseini VA, Wessman S, Hurtig K, Karlsson L (2016) Nitrogen loss and effects on microstructure in multipass TIG 
welding of a super duplex stainless steel. Mater Des 98:88-97. https://doi.org/10.1016/j.matdes.2016.03.011

[16] Baghdadchi A, Hosseini VA, Hurtig K, Karlsson L (2020) Promoting austenite formation in laser welding of duplex stainless steel-impact of shielding gas and laser reheating. Weld World 65:499-511. https://doi.org/10.1007/s40194-02 0-01026-7

[17] Davidson K, Singamneni S (2016) Selective laser melting of duplex stainless steel powders: an investigation. Mater Manuf Process 31:1543-1555. https://doi.org/10.1080/1042 6914.2015.1090605

[18] Papula S, Song M, Pateras A et al (2019) Selective laser melting of duplex stainless steel 2205: effect of post-processing heat treatment on microstructure, mechanical properties, and corrosion resistance. Mater (Basel) 12:1-15. h ttps://doi.org/10.3390/ma12152468

[19] Hengsbach F, Koppa P, Duschik K et al (2017) Duplex stainless steel fabricated by selective laser melting microstructural and mechanical properties. Mater Des 133:136-142. https://doi.org/10.1016/j.matdes.2017.07.046

[20] Hosseini VA, Högström M, Hurtig K et al (2019) Wire-arc additive manufacturing of a duplex stainless steel: thermal cycle analysis and microstructure characterization. Weld World 63:975-987. https://doi.org/10.1007/s40194-019-007 $35-y$

[21] Zhang X, Wang K, Zhou Q et al (2020) Element partitioning and electron backscatter diffraction analysis from feeding wire to as-deposited microstructure of wire and arc additive manufacturing with super duplex stainless steel. Mater Sci Eng A 773:138856. https://doi.org/10.1016/j.msea.2019. 138856

[22] Posch G, Chladil K, Chladil H (2017) Material properties of CMT - metal additive manufactured duplex stainless steel blade-like geometries. Weld World 61:873-882. https://doi. org/10.1007/s40194-017-0474-5

[23] Lervåg M, Sørensen C, Robertstad A et al (2020) Additive manufacturing with superduplex stainless steel wire by $\mathrm{cmt}$ process. Metals (Basel) 10:5-12. https://doi.org/10.3390/me t10020272

[24] Stuzer J, Totzauer T, Wittig B et al (2019) GMAW cold wire technology for adjusting the manufactured duplex stainless steel components. Metals (Basel) 9:564-583

[25] Kotecki DJ (1989) Heat treatment of duplex stainless steel weld metals. Weld J 68:431s-441s

[26] Tan H, Wang Z, Jiang Y et al (2011) Annealing temperature effect on the pitting corrosion resistance of plasma arc welded joints of duplex stainless steel UNS S32304 in 1.0M $\mathrm{NaCl}$. Corros Sci 53:2191-2200. https://doi.org/10.1016/j.c orsci.2011.02.041
[27] Tavares SSM, Scandian C, Pardal JM et al (2010) Failure analysis of duplex stainless steel weld used in flexible pipes in off shore oil production. Eng Fail Anal 6:1500-1506

[28] Hosseini VA, Hurtig K, Karlsson L (2017) Effect of multipass TIG welding on the corrosion resistance and microstructure of a super duplex stainless steel. Mater Corros 68:405-415. https://doi.org/10.1002/maco.201609102

[29] A Hosseini V, Hurtig K, Eyzop D et al (2019) Ferrite content measurement in super duplex stainless steel welds. Weld World 63:551-563. https://doi.org/10.1007/s40194-018-006 81-1

[30] Baghdadchi A, Hosseini VA, Karlsson L (2021) Identification and quantification of martensite in ferritic-austenitic stainless steels and welds. J Mater Res Technol 15:3610-3621. https://doi.org/10.1016/j.jmrt.2021.09.153

[31] Baghdadchi A, Hosseini VA, Bermejo MAV et al (2021) Wire laser metal deposition additive manufacturing of duplex stainless steel components - development of a systematic methodology. Mater (Basel) 14:7170. https://doi. org/10.3390/ma14237170

[32] Kim ST, Lee IS, Kim JS et al (2012) Investigation of the localized corrosion associated with phase transformation of tube-to-tube sheet welds of hyper duplex stainless steel in acidified chloride environments. Corros Sci 64:164-173. h ttps://doi.org/10.1016/j.corsci.2012.07.014

[33] Ogawa T, Koseki T (1989) Effect of composition profiles on metallurgy and corrosion behavior of duplex stainless steel weld metals. Weld J 68:181

[34] Gooch TG (1983) Weldability of duplex ferritic-austenitic stainless steel in Conf. In: Proceedings of the Duplex stainless steels. p 573

[35] Roy S, Silwal B, Nycz A et al (2021) Investigating the effect of different shielding gas mixtures on microstructure and mechanical properties of 410 stainless steel fabricated via large scale additive manufacturing. Addit Manuf 38:101821. https://doi.org/10.1016/j.addma.2020.101821

[36] Hosseini VA, Karlsson L (2019) Physical and kinetic simulation of nitrogen loss in high temperature heat affected zone of duplex stainless steels. Materialia 6:100325. https://doi. org/10.1016/j.mtla.2019.100325

[37] Valiente Bermejo MA, Hurtig K, Eyzop D, Karlsson L (2019) A new approach to the study of multi-pass weldsmicrostructure and properties of welded 20-mm-thick superduplex stainless steel. Appl Sci. https://doi.org/10.339 0/app9061050

[38] Hosseini VA, Hurtig K, Karlsson L (2020) Bead by bead study of a multipass shielded metal arc-welded super-duplex stainless steel. Weld World 64:283-299. https://doi.org/10. 1007/s40194-019-00829-7 
[39] Ramirez AJ, Brandi SD, Lippold JC (2004) Secondary austenite and chromium nitride precipitation in simulated heat affected zones of duplex stainless steels. Sci Technol Weld Join 9:301-313. https://doi.org/10.1179/ 136217104225021715

[40] Cederberg E, A Hosseini V, Kumara C, Karlsson L (2020) Physical simulation of additively manufactured super duplex stainless steels - microstructure and properties. Addit Manuf. https://doi.org/10.1016/j.addma.2020.101269

[41] TMR Stainless (2014) Practical Guidelines for the Fabrication of Duplex Stainless Steels

[42] Hosseini VA, Karlsson L, Engelberg D, Wessman S (2018) Time-temperature-precipitation and property diagrams for super duplex stainless steel weld metals. Weld World 62:517-533. https://doi.org/10.1007/s40194-018-0548-Z

[43] Park S, Shin B, Park J et al (2019) Effect of austenite morphology on the electrochemical properties of super duplex stainless UNS S 32750. Int J Electrochem Sci 14:5386-5395

[44] Kuhn H, Medlin D (2000) ASM HANDBOOK. Volume 8: Mechanical Testing and Evaluation. ASM International, Member/Customer Service Center, Materials Park, OH 44073-0002, USA

[45] Materials Sandvik (2013) Duplex Stainless Steel 2205. In: SANDVIK. https://www.materials.sandvik/en/materials-cent er/material-datasheets/tube-and-pipe-seamless/saf-2205/

[46] Tian Y, Lin S, Ko JYP et al (2018) Micromechanics and microstructure evolution during in situ uniaxial tensile loading of TRIP-assisted duplex stainless steels. Mater Sci Eng A 734:281-290. https://doi.org/10.1016/j.msea.2018.0 7.040

Publisher's Note Springer Nature remains neutral with regard to jurisdictional claims in published maps and institutional affiliations. 